\title{
Fusões, aquisições e gerenciamento de resultados: uma revisão sistemática envolvendo diferentes categorias analíticas
}

\section{Mergers, acquisitions and earnings management: a systematic review involving different analytical categories}

\author{
OSCAR NETO DE ALMEIDA BISPO* \\ SAULO CARDOSO MAIA** \\ LEANDRO EDUARDO VIEIRA BARROS*** \\ FRANCISVAL DE MELO CARVALHO ${ }^{* * * *}$
}

\section{RESUMO}

O objetivo geral deste artigo foi realizar uma revisão bibliográfica sistemática nos artigos disponíveis na base Web of Science que pesquisaram o gerenciamento de resultados (EM) concomitante às transações de fusões e aquisições (F\&A). Especificamente: i) verificar quais foram as principais discussões sobre o tema; ii) criar categorias analíticas para ordenar as discussões; e iii) elaborar uma síntese do conhecimento existente sobre o assunto. A amostra envolveu 40 artigos registrados entre janeiro de 1945 e novembro de 2016. Foi usado o método de revisão bibliográfica sistemática para a análise de conteúdo qualitativa. As estratégias de busca utilizaram rótulos de campo e operadores boolianos com expressões definidas a priori. Os resultados apontaram

* Universidade Federal de Lavras (UFLA). Departamento de Administração e Economia Programa de Pós-Graduação em Administração. oscar@ufsj.edu.br

** Universidade Federal de Lavras (UFLA). Departamento de Administração e Economia Programa de Pós-Graduação em Administração.

*** Universidade Federal de Lavras (UFLA). Departamento de Administração e Economia Programa de Pós-Graduação em Administração. leandro.barros@ifsudestemg.edu.br

**** Universidade Federal de Lavras (UFLA). Departamento de Administração e Economia Programa de Pós-Graduação em Administração. francarv@dae.ufla.br 
11 categorias analíticas e, pelo menos, 43 elementos essenciais inerentes a elas. Grande maioria dos resultados mostra que há interesse na utilização do EM próximo aos anúncios e efetivação das F\&A. Diversos pesquisadores analisaram o EM voltado para manipulação dos accruals no sentido de elevar o lucro. Outros, em menor quantidade, introduziram a importância de verificar as manipulações de atividades reais com base na DFC. Trabalhos futuros poderiam relacionar information asymmetry com as transações de F\&A e as potenciais interferências do EM, tanto por accruals quanto por atividades reais.

Palavras-chave: Fusões e aquisições; gerenciamento de resultados; revisão sistemática; análise de conteúdo.

\section{Abstract}

This paper aimed to perform a systematic review on papers available in the Web of Science database that researched earnings management (EM) concomitantly with mergers and acquisitions transactions (M\&A). It specifically aimed: i) checking which were the main discussions on the subject; ii) creating analytical categories in order to organize the discussions; and iii) elaborating a summary of existing knowledge about the subject. The sample involved 40 papers registered from January 1945 to November 2016. A systematic review method was used to do a qualitative content analysis. The search strategies used field labels and Boolean operators with priori defined expressions. The results showed 11 analytical categories and at least 43 essential inherent elements of these categories. Most of the results shows that there is interest in using EM next to announcements and execution of M\&A. Several researchers analyzed EM aiming manipulation of accruals in order to increase profit. Others, to a lesser extent, introduced the importance of verifying the real activities management based on cash flow statements. Future work could relate informational asymmetry with M\&A transactions and potential EM interference, both accruals and real activities.

Keywords: Mergers and acquisitions; earnings management; systematic review; content analysis. 


\section{INTRODUÇÃo}

Dado o número de atividades de fusões e aquisições $(\mathrm{F} \& \mathrm{~A})^{1}$, em âmbito internacional e também nacional, o mercado tem cada vez mais se preocupado com o efeito dessas transações. Em geral, o centro das discussões se situa nos conflitos e forças que levaram as companhias a optar por esse tipo de transação e quais são as expectativas sobre o futuro após esses complexos eventos corporativos.

Campbell, Sirmon e Schijven (2016) afirmam que F\&A representam estratégias-chave que os gestores podem empreender na esperança de melhorar ou sustentar o desempenho de suas companhias. Consequentemente, pesquisadores têm focado esforços significativos em revelar quais são os determinantes da criação (destruição) de valor em corporações que optaram por F\&A e, também, os efeitos dessas transações na reação dos investidores.

Autores como Jensen (1986), Roll (1986), Bradley, Desai e Kim (1983), Berkovitch e Narayanan (1993), Seth, Song e Pettit (2000), Weston, Siu e Johnson (2001) se empenharam em entender os determinantes de aumento (diminuição) de valor em empresas envolvidas nesses processos. Suas pesquisas corroboram que empresas deveriam empreender F\&A principalmente para se beneficiar da criação de valor a partir das sinergias geradas.

Nesse arcabouço, o fortalecimento da posição de mercado, resposta a choques setoriais, transferência de conhecimento organizacional, economias de escala, exploração da informação assimétrica e eficiência nos custos de transação são fortes direcionadores de criação de valor a partir de F\&A. No entanto, fatores como os conflitos de agência, ainda de difícil compreensão e/ou constatação, podem não contribuir para a criação de valor, mas sim para a destruição de valor das empresas.

Sobre esses conflitos, Jensen (1986) postula que com o crescimento da companhia - a partir de F\&A - cresce o poder do gestor, a julgar pelo maior volume de recursos sob seu controle. É de se

1 Cabe salientar que, tanto nacional quanto internacionalmente, grande parte das pesquisas considera que no rol das F\&A (em inglês conhecidas como mergers and acquisitions - M\&A) estão classificadas transações que envolvem combinações de negócios, aquisições, compras, joint ventures, fusões e incorporações. Neste artigo essas classificações também foram utilizadas. 
ponderar que, em promovendo transações de F\&A para aumentar a dimensão dela, existe a possibilidade de proporcionar maior poder ao gestor e, consequentemente, de aumento na assimetria informacional já existente. Os problemas de agência podem surgir quando os gestores buscam o crescimento excessivo visando a promover interesses pessoais. Berkovitch e Narayanan (1993), Seth, Song e Pettit (2000) e Weston, Siu e Johnson (2001) expõem que a assimetria informacional e o conflito de agência são um dos condicionantes para a ocorrência da redução de valor de companhias adquirentes que passaram por $\mathrm{F} \& \mathrm{~A}$.

Nesse contexto de assimetria informacional e conflitos de interesses, a pesquisa de Becker et al. (1998) contribuiu para evidenciar que os gestores possuem incentivos naturais para ajustar os resultados contábeis (gerenciamento de resultados ou earnings management - EM), visando a melhorar o valor da companhia e/ou o próprio bem-estar. Aproveitando-se da assimetria de informações eles fazem escolhas contábeis oportunistas, gerando conflitos de interesses nas organizações e podendo trazer resultados negativos aos investidores e, consequentemente, ao mercado. Dessa forma, a seleção dos melhores investimentos seria tomada de forma adversa à realidade apresentada pelas empresas, tornando-se difícil distinguir empresas de alto risco daquelas de baixo risco - ex ante ao anúncio e decisão de engajar em transações que envolvem F\&A.

Ou seja, o interesse principal dos gestores seria realizar o EM nos relatórios contábil-financeiros para retratar uma realidade da companhia que não é a verdadeira. Healy e Wahlen (1999, p. 368) mencionam que o EM

ocorre quando gestores usam do julgamento na divulgação financeira e na estruturação das transações para alterar os relatórios financeiros. [...] [A finalidade do EM seria] enganar alguns usuários da informação contábil sobre o desempenho econômico subjacente da companhia ou para influenciar os resultados contratuais que dependem dos números contábeis relatados.

Na visão de Mohanram (2003) os gestores praticam o EM desejando atingir determinados benchmarks relacionados ao desempenho 
da companhia, por exemplo: atender às previsões do desempenho futuro; atender às expectativas dos analistas; e alcançar resultados positivos ou metas que proporcionem maiores compensações aos gestores. Logo, percebe-se que o EM pode ser uma fonte de possibilidades para os gestores evidenciarem resultados visando a seduzir os acionistas da companhia a concordarem com a realização de F\&A, haja vista que estes não percebem a ação oportunista daqueles.

A partir do exposto, torna-se relevante a realização de estudos que possam contribuir com a fronteira do conhecimento no que tange às implicações da assimetria informacional e, principalmente, aos impactos do EM nas transações de F\&A. Especificamente, é importante levantar aquilo que já se produziu sobre o tema, principalmente quando se tem a prática de EM concomitante com tais transações; ou seja, considerando a importância das F\&A no cenário mundial, como se encontra o estado da arte das pesquisas que relacionam o earnings management com as transações de F\&A?

Tendo em vista responder essa questão, o estudo delimitou como objetivo geral realizar uma revisão bibliográfica sistemática nos artigos que pesquisaram o EM em operações de F\&A disponíveis na base Web of Science. Especificamente, os objetivos englobaram: i) verificar quais foram as principais discussões sobre o tema compreendidas nos artigos levantados; ii) criar categorias analíticas para ordenar as discussões sobre F\&A e EM investigadas pelos pesquisadores; e iii) elaborar uma síntese do conhecimento existente sobre o assunto.

A relevância da pesquisa está em proporcionar insights para novos estudos sobre F\&A, auxiliando a tomada de decisões de gestores, investidores e outros usuários das informações contábil-financeiras. Ademais, o estudo desvenda um arcabouço de possibilidades em que o EM é utilizado e sua influência na provável destruição de valor de empresas envolvidas em F\&A.

Após a contextualização do tema, problema e objetivos de pesquisa, este artigo foi estruturado da seguinte maneira: a plataforma teórica do estudo traz as motivações para F\&A e pontos relevantes sobre oportunismo, conflitos de interesses e gerenciamento de resultados (EM); em seguida, a metodologia caracteriza o tipo de pesquisa, objeto de estudo e técnicas de coleta e análises dos dados; 
e, posteriormente, são debatidos os principais achados. Por fim, são contempladas as considerações para fechamento do trabalho e continuidade de pesquisas futuras.

\section{CONFLITOS DE INTERESSES, GERENCIAMENTO DE RESULTADOS E F\&A}

Conforme explicitado por Sunder (2002), as empresas podem ser vistas como um conjunto de contratos entre as partes interessadas, os quais devem convergir para o cumprimento das expectativas dos agentes. Entretanto, os conflitos de interesses entre os agentes podem levar a perdas substanciais para as organizações. Tais conflitos são abordados pela teoria da agência, a qual considera, entre outras proposições, que o comportamento dos gestores e, consequentemente, a divulgação de seus atos e decisões podem ser conflitantes com o interesse dos stakeholders.

Para Trapp (2009), o conflito de agência surge quando os interesses dos agentes ligados à empresa são divergentes dos interesses dos acionistas. Por conseguinte, o acionista deve ter o maior número possível de instrumentos para evitar que os interesses pessoais dos administradores prejudiquem a organização. Jensen e Meckling (2008) informam que no contexto do conflito de agência observa-se que acionistas e administradores, uma vez que possuem interesses particulares, podem conflitar quanto à escolha da melhor estratégia corporativa. Essas divergências impactariam a reação do mercado, o risco e o retorno das ações diante de relatórios contábeis divulgados.

Haja vista que os relatórios contábeis são gêneros de discurso, os gestores podem se utilizar de comportamento oportunista para manipular informações contábil-financeiras com vistas a retratar uma realidade da empresa que não é a verdadeira, impactando diretamente os resultados evidenciados ao mercado para atender aos interesses particulares. Pretendendo representar um bom desempenho econômico-financeiro da empresa e suprir os usuários das demonstrações contábeis com as informações necessárias à sua tomada de decisão, os gestores podem estar propensos a manipular os relatórios contábeis.

Shleifer e Vishny (1989) complementam que há boas razões para acreditar que a maximização de valor da empresa nem sempre é o objetivo do gestor. Em certos momentos ele orientará as decisões 
de F\&A com base em suas percepções ou desejos pessoais, movido por orgulho excessivo, cometendo equívocos na valorização das empresas-alvo e engajando em $\mathrm{F} \& \mathrm{~A}$ mesmo sem potencial de ganho. Além disso, pode ser que, levado pelo desejo pessoal, utilize sua discricionariedade para gerenciar os resultados contábeis com o objetivo de atender a interesses particulares.

Utilizando-se de informações assimétricas os gestores têm a possibilidade de colocar em prática o EM próximo de períodos que antecedem decisões econômicas importantes, abastecendo o mercado com perspectivas falsas, que não poderão ser sustentadas no longo prazo. Dye (1988) evidenciou que a existência de informações assimétricas entre gestores e acionistas é uma condição necessária para existir o EM, porque acionistas não podem observar perfeitamente o desempenho e os prospectos futuros de uma empresa em um ambiente no qual possuem informações piores que a dos gestores. Nesse ambiente, a administração tem habilidade discricionária para controlar os resultados contábeis.

Na opinião de Cupertino, Martinez e Costa Jr. (2015, p. 322), caso "os investidores não sejam conscientes das implicações do earnings management, eles não serão capazes de fazer os ajustes necessários ao formar suas expectativas sobre o desempenho futuro de uma entidade". Esses autores complementam: "se os investidores alocam recursos em ativos cujos resultados foram manipulados, eles ficarão frustrados quando o desempenho futuro for diferente de suas expectativas" (CUPERTINO; MARTINEZ; COSTA JR., 2015, p. 322).

Nesse contexto, diversas pesquisas buscaram evidenciar as implicações do EM para as transações de F\&A. Há fortes evidências de que as companhias - tanto adquirentes quanto alvos - manipulam os resultados contábeis em períodos que antecedem uma F\&A; devido a essa postura, muitas transações de F\&A promovem destruição de valor no longo prazo. Os resultados dos estudos sugerem que, em muitos casos, o baixo desempenho de longo prazo, ex post a F\&A, é parcialmente atribuído à reversão dada pelo EM ex ante a F\&A.

Ao se considerarem os conflitos de interesses envolvidos em diversas transações no mercado de capitais e a possibilidade de o oportunismo dos agentes ocasionar perdas econômico-financeiras aos stakeholders, torna-se importante pesquisar os fatores que influenciam os resultados nas operações de F\&A. Avaliar nas empresas 
proponentes e empresas-alvo a existência de relações significativas entre os motivos pela adesão às F\&A e a criação ou destruição de valor é importante para os acionistas e o mercado de capitais, pois pode aperfeiçoar as escolhas sobre investir ou desinvestir em determinadas corporações.

Logo, com base no exposto, torna-se importante levantar pesquisas sobre as F\&A, investigando suas inter-relações com as ações oportunistas de EM. A intenção é ratificar a relevância das informações contábeis no processo de tomada de decisões em transações que envolvem F\&A, as quais podem ser motivadas por oportunismo e conflitos de interesses causados pela assimetria informacional.

\section{Procedimentos Metodológicos}

\subsection{Caracterização da pesquisa e objeto de estudo}

O estudo é considerado do tipo exploratório e visa a trazer lacunas significativas para posteriores pesquisas. Como tal, essa pesquisa não requer a elaboração de hipóteses a serem testadas, restringindo-se a definir objetivos e a buscar mais informações sobre determinado assunto em questão.

O objeto de estudo foram os artigos publicados em periódicos da base Web of Science que investigaram as transações de F\&A concomitantemente com a ocorrência de EM. O processo de amostragem envolveu o método intencional. Foram considerados todos os registros de artigos entre janeiro de 1945 e novembro de 2016.

\subsection{Técnicas de coleta e análise dos dados}

A pesquisa se baseou no método qualitativo de revisão bibliográfica sistemática. Assim como outros tipos de estudo de revisão, trata-se de uma forma de pesquisa que utiliza como fonte de dados a literatura sobre determinado tema. Essa investigação disponibiliza um resumo das evidências relacionadas a uma estratégia de intervenção específica, mediante a aplicação de métodos explícitos e sistematizados de busca, apreciação crítica e síntese da informação selecionada (SAMPAIO; MANCINI, 2007).

Conforme Bereton et al. (2007), por meio da revisão bibliográfica sistemática o pesquisador pode avaliar rigorosamente, e de forma confiável, pesquisas já realizadas no âmbito de um tema específico. 
Para Biolchini et al. (2007, p. 136), a revisão bibliográfica sistemática “é o meio pelo qual o pesquisador pode realizar um mapeamento do conhecimento existente e previamente desenvolvido" visando elaborar uma síntese do conhecimento existente sobre o assunto. A revisão sistemática foi particularmente útil para integrar as informações de um grupo de estudos realizados sobre F\&A concomitantemente ao EM, visando a apresentar resultados conflitantes e/ou coincidentes. Essa abordagem pode identificar temas que necessitam de evidências complementares para orientar investigações futuras.

A realização da revisão bibliográfica sistemática na base Web of Science seguiu os estágios elencados no Quadro 1.

Quadro 1: Estágios da revisão sistemática

\begin{tabular}{|l|l|}
\hline Estágio & Passos/Descrição \\
\hline $\begin{array}{l}\text { Caracterização } \\
\text { do campo de } \\
\text { pesquisa }\end{array}$ & $\begin{array}{l}\text { 1. Enquadramento da questão e objetivos da pesquisa } \\
\text { 2. Escolha da base científica e journals } \\
\text { 3. Delimitação dos termos referentes ao campo F\&A conco- } \\
\text { mitante ao EM }\end{array}$ \\
\hline $\begin{array}{l}\text { Pesquisa na } \\
\text { base Web of } \\
\text { Science }\end{array}$ & $\begin{array}{l}\text { 4. Busca do campo F\&A em conjunto com termos sobre EM } \\
\text { 6. Filtro I: apenas artigos científicos }\end{array}$ \\
\hline $\begin{array}{l}\text { 7. Filtro II: todos os anos contidos na base } \\
\text { 8. Filtro III: todas as áreas do conhecimento } \\
\text { 9. Filtro IV: todas as línguas }\end{array}$ \\
\hline amostra & $\begin{array}{l}\text { 10. Download e organização das referências no EndNote Web } \\
\text { 11. Leitura do abstract para adequação da amostra ao objeto } \\
\text { de estudo } \\
\text { 12. Download dos artigos em seus respectivos journals }\end{array}$ \\
\hline $\begin{array}{l}\text { Análise de con- } \\
\text { teúdo qualita- } \\
\text { tiva das produ- } \\
\text { ções científicas }\end{array}$ & $\begin{array}{l}\text { 13. Leitura da introdução, resultados e conclusões } \\
\text { 14. Análise do que foi considerado e criação das categorias } \\
\text { analicas } \\
\text { 15. Diagramação/esquematização dos elementos essenciais } \\
\text { 16. Síntese do conhecimento existente sobre o assunto }\end{array}$ \\
\hline
\end{tabular}

Fonte: Elaborado pelos autores.

2 O EndNote Web é um software on-line que permite o armazenamento e a organização de referências obtidas nas buscas em bases de dados e inclusão de referências de forma manual. Torna possível a inclusão automática de citações e referências quando da elaboração do texto, e mudança para diversos estilos de normalização (ESTORNIOLO FILHO et al., 2010). 
Conforme exposto no Quadro 1, a caracterização do campo de pesquisa levou em consideração a definição da amostra a ser estudada para enquadramento da questão e os objetivos. Foram especificados a priori os artigos publicados com o tema F\&A em conjunto com operações de EM compreendidos na base Web of Science. Além disso, também se delimitaram as expressões para orientação na busca por artigos que envolveram o campo de conhecimento alusivo às F\&A em conjunto com EM. Para tanto, as seguintes expressões foram utilizadas nas buscas: M\&A, F\&A, mergers, acquisition, takeover, fusões, aquisições, fusão, aquisição, business combination, combinação de negócios, earnings management, earnings manipulation, manage earnings, real activities manipulation, real earnings management, balance sheet management, accounting choices, creative accounting, accruals, management choices, accounting treatment e opportunistic choice.

$\mathrm{O}$ uso desses termos justifica-se por estarem presentes em estudos relevantes sobre o campo de pesquisa, tais como: Dye (1988), Jones (1991), Christie e Zimmerman (1994), Dechow, Sloan e Sweeney (1995), Becker et al. (1998), Erickson e Wang (1999), Healy e Wahlen (1999), Heron e Lie (3002), Hribar e Collins (2002), Louis (2004), Gong, Louis e Sun (2008), Botsari e Meeks (2008) e Cupertino, Martinez e Costa Jr. (2015), entre outros.

Em seguida foram realizadas pesquisas na base Web of Science, e as estratégias e condução da busca utilizaram rótulos de campo (TS= tópico) e operadores boolianos (AND e OR). O campo pesquisado foi aquele que englobou os estudos sobre F\&A concomitante com as expressões propostas, da seguinte forma (Figura 1).

Os seguintes filtros foram utilizados: pesquisar apenas por artigos científicos (filtro 1) publicados em todos os anos contidos na base Web of Science (filtro 2), em qualquer área do conhecimento (filtro 3) e envolvendo todas as línguas (filtro 4).

No estágio de seleção da amostra foram encontradas 251 referências em diversas áreas do conhecimento, organizadas no EndNote Web e realizada a leitura do abstract para adequação da amostra. Foram eliminados 211 artigos, pois, apesar de conterem pelo menos uma das expressões elencadas na Figura 1, tratavam de assuntos não relacionados ao objeto de estudo (saúde, agricultura, psicologia, 
Figura 1: Estratégias de busca ${ }^{3}$ na base Web of Science

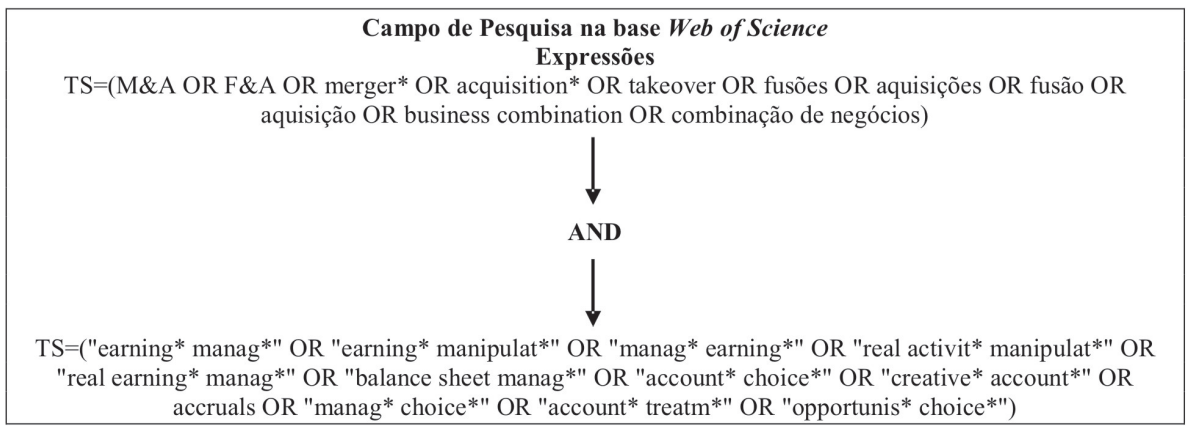

Fonte: Elaborada pelos autores.

educação, sociologia, engenharias e outras áreas de conhecimento). Logo, restaram 40 artigos [ver Apêndice], principalmente nas áreas de finanças, negócios, economia, administração e direito. Em seguida foi realizado download desses 40 artigos para posterior análise.

Seguindo os passos elencados no Quadro 1, os 40 artigos foram submetidos ao processo de análise de conteúdo qualitativa, conforme proposto por Finfigeld-Connett (2014), com o uso de memorandos reflexivos e diagramação. De acordo com a autora, memorandos reflexivos e diagramação são importantes ao executar construção de conhecimento e geração de teoria via revisão sistemática qualitativa. Como implicação desses processos, resultados são integrados, interpretados e sintetizados entre os estudos, bem como interconexões entre os elementos resultantes são explicadas. Por meio de memorandos reflexivos e diagramação, em particular, estruturas teóricas existentes são aprimoradas e o desenvolvimento de conhecimento ocorre.

Memorandos reflexivos são notações escritas sobre os dados "rascunhados" com a análise. Por meio desse processo, resultados codificados são organizados, esclarecidos, integrados e interpretados. $\mathrm{O}$ resultado esperado é a síntese dos achados entre os estudos. $\mathrm{Na}$

3 Procedimento similar foi realizado preliminarmente para apurar a existência de artigos que trabalharam metassíntese, meta-análise e/ou revisão sistemática sobre o tema. Para tanto, foi adicionado à estratégia de busca o comando AND TS=(meta synthesis OR meta-analysis OR systematic review). Os resultados não identificaram artigos com tais características. 
diagramação, o revisor busca identificar como códigos, categorias e memorandos que os acompanham parecem se relacionar e se encaixar. Esse processo é uma forma adicional de documentação das decisões de análise de dados (FINFIGELD-CONNETT, 2014).

Ou seja, foram extraídos conteúdos relevantes a partir da leitura em profundidade dos resumos, introdução, resultados e conclusões dos 40 artigos. Categorias analíticas foram criadas e detalhadas para facilitar a análise de conteúdo qualitativa. Em consequência, foi realizada a esquematização dos elementos essenciais contidos em cada categoria analítica para refletir os assuntos mais discutidos em cada artigo. Por fim, relacionaram-se os aspectos principais dos artigos, seus conflitos e suas similaridades, visando a sintetizar o conhecimento existente sobre o assunto e tecer insights para novos estudos sobre o tema.

\section{ANÁliSE E DISCUSSÃo DOS RESULTADOS}

Os 40 artigos foram avaliados e as categorias analíticas criadas. Ressalta-se que, dentre os periódicos pesquisados, há predominância das áreas de business, finance e economics. Também se constatou que os Estados Unidos contêm o maior número de periódicos que tratam simultaneamente dos temas F\&A e EM. No que tange ao número de citações dos artigos analisados, "Errors in estimating accruals: Implications for empirical research", de autoria de Hribar e Collins (2002), foi o mais citado. Esse resultado demonstra a preocupação e o interesse de outros pesquisadores com os erros de estimação dos accruals e suas consequentes implicações.

Nesse cenário, Cupertino, Martinez e Costa Jr. (2015, p. 312) mostram em descoberta recente que o EM “também é realizado por meio de atividades reais, ou seja, tomando ações que se desviam das práticas operacionais normais". No entanto, há uma concentração na utilização dos accruals para aferir o EM nos componentes do lucro. Os investidores que não avaliam esses componentes - separadamente, pelos fluxos de caixa e pelos accruals do balanço patrimonial - tenderão a sobrevalorizar as empresas com altos accruals e subvalorizar aquelas com baixos accruals, conforme apontam Daniel e Hirshleifer (2015).

Após esse breve contexto, ao extrair os conteúdos relevantes e similaridades, constataram-se 11 categorias analíticas e, pelo menos, 43 elementos essenciais discutidos pelos autores dentro dessas categorias, conforme mostra o Quadro 2. 
Quadro 2: Categorias analíticas e respectivos elementos essenciais

\begin{tabular}{|c|c|}
\hline $\begin{array}{l}\text { Categorias } \\
\text { analíticas }\end{array}$ & Elementos essenciais discutidos pelos autores \\
\hline $\begin{array}{l}\text { Desempenho no } \\
\text { longo prazo, F\&A } \\
\text { e EM }\end{array}$ & \begin{tabular}{|l|} 
Retornos anormais \\
Fluxo de caixa livre \\
Governança corporativa \\
\end{tabular} \\
\hline $\begin{array}{l}\text { Conselho Admi- } \\
\text { nistrativo, EM e } \\
\text { F\&A }\end{array}$ & $\begin{array}{l}\text { Bônus concedidos aos diretores } \\
\text { Experiência do diretor na indústria } \\
\text { Contaminação de diretores por EM } \\
\text { Monitoramento do Conselho Administrativo } \\
\text { Security Exchange Commission Enforcement } \\
\text { Oportunismo gerencial e governança corporativa } \\
\text { Diretores independentes e diretores compartilhados }\end{array}$ \\
\hline $\begin{array}{l}\text { Normas Contá- } \\
\text { beis, EM e F\&A }\end{array}$ & $\begin{array}{l}\text { Goodwill e impairment } \\
\text { Tratamento contábil e perspectiva histórica } \\
\text { Oportunismo gerencial e governança corporativa } \\
\text { International Financial Reporting Standard } 3 \text { (IFRS 3) }\end{array}$ \\
\hline $\begin{array}{l}\text { F\&A stock-for-sto- } \\
\text { ck e EM }\end{array}$ & $\begin{array}{l}\text { F\&A stock-for-stock entre companhias independentes } \\
\text { Desempenho } \\
\text { Real Earnings Management } \\
\text { Cross-border, língua, cultura e religião } \\
\text { Accruals e qualidade dos padrões contábeis } \\
\text { Ambientes políticos e legais da companhia-alvo } \\
\text { Target listadas e não listadas em bolsa de valores } \\
\text { Oportunismo gerencial e governança corporativa } \\
\text { Cronograma dos anúncios das F\&A e dia da semana } \\
\text { F\&A stock-for-stock entre companhias associadas } \\
\text { F\&A stock-for-stock e desdobramento de ações } \\
\text { F\&A stock-for-stock e governança corporativa } \\
\text { F\&A stock-for-stock e ações judiciais } \\
\text { F\&A stock-for-stock e procura por compradores } \\
\text { Real Earnings Management } \\
\text { Retornos anormais e desempenho } \\
\text { Due diligence e diferenças entre países } \\
\text { F\&A stock-for-stock, disclosure voluntário e conference call }\end{array}$ \\
\hline $\begin{array}{l}\text { F\&A e erros na } \\
\text { estimação do EM }\end{array}$ & Accruals anormais e Real Earnings Management \\
\hline
\end{tabular}




\begin{tabular}{|l|l|}
\hline $\begin{array}{l}\text { Categorias } \\
\text { analíticas }\end{array}$ & Elementos essenciais discutidos pelos autores \\
\hline $\begin{array}{l}\text { Qualidade da } \\
\text { auditoria, F\&A e } \\
\text { EM }\end{array}$ & $\begin{array}{l}\text { Mercados emergentes } \\
\text { Value Relevance e risco informacional } \\
\text { PricewaterhouseCoopers e Certified Public Accountant }\end{array}$ \\
\hline $\begin{array}{l}\text { Tomada de con- } \\
\text { trole e EM }\end{array}$ & $\begin{array}{l}\text { Staggered Board } \\
\text { Prêmio e incerteza assimétrica } \\
\text { Quiet Life Theory e Alignment Theory } \\
\text { Takeover Protection Statute e Poison Pill } \\
\text { Qualidade dos lucros e Real Earnings Management }\end{array}$ \\
\hline $\begin{array}{l}\text { Sarbanes-Oxley, } \\
\text { F\&A e EM }\end{array}$ & $\begin{array}{l}\text { Regulamentação } \\
\text { Escândalos contábeis } \\
\text { Qualidade dos lucros }\end{array}$ \\
\hline $\begin{array}{l}\text { Pesquisa e Desen- } \\
\text { volvimento, F\&A } \\
\text { e EM }\end{array}$ & $\begin{array}{l}\text { Retornos anormais } \\
\text { Baixas contábeis e P\&D em processo }\end{array}$ \\
\hline $\begin{array}{l}\text { Diversificação } \\
\text { geográfica e } \\
\text { industrial, F\&A } \\
\text { e EM }\end{array}$ & Accruals anormais e assimetria informacional \\
\hline $\begin{array}{l}\text { Cobertura dos } \\
\text { analistas, F\&A e } \\
\text { EM }\end{array}$ & $\begin{array}{l}\text { Quasi-Experimento e experiment natural } \\
\text { Real Earnings Management }\end{array}$ \\
\hline Fon Dados daperatisar
\end{tabular}

Fonte: Dados da pesquisa.

Apoiando-se no Quadro 2, os tópicos seguintes expõem a síntese dos achados mais relevantes dos artigos pesquisados.

\subsection{Síntese do conhecimento existente sobre o assunto}

\subsubsection{Desempenho no longo prazo, F\&A e EM}

Chen, Liu e Chen (2014) analisaram o desempenho de longo prazo das ações de adquirentes em F\&A e os determinantes das diferenças de desempenho. Foram testadas hipóteses de ajuste, foco, fluxo de caixa livre, desempenho gerencial anterior, EM e governança corporativa.

Os achados de Chen, Liu e Chen (2014) foram: (i) ajuste - há retornos anormais negativos no longo prazo; (ii) foco - os retornos 
em F\&A relacionadas são maiores do que aquelas aquisições não relacionadas; (iii) fluxo de caixa livre - não há diferença entre os adquirentes com alto fluxo de caixa livre e aqueles com baixo fluxo de caixa livre, independentemente do alto ou baixo $Q$ de Tobin; (iv) desempenho gerencial anterior - os adquirentes com desempenho superior anterior têm retornos anormais pós-F\&A mais fracos do que adquirentes com desempenho inferior anterior; (v) earnings management - os retornos anormais das ações no longo prazo, pósF\&A, são negativamente relacionados a seus accruals anormais; (vi) governança corporativa - os retornos anormais das ações no longo prazo de adquirentes com maiores porcentagens de conselheiros independentes e de propriedade institucional são maiores do que aqueles com porcentagens menores. Os adquirentes com níveis mais elevados de entrincheiramento gerencial ganham retornos anormais das ações no longo prazo mais elevados.

\subsubsection{Conselho Administrativo, EM e F\&A}

Conforme explicitado por Christie e Zimmerman (1994), os gestores estarão propensos a se engajar em atividades oportunistas por duas razões: i) para aumentar a compensação via esquemas formais e informais que estejam lastreados em pagamento de executivos a partir do lucro reportado; ii) para reduzir a probabilidade de o CEO ser removido devido à tomada de decisões errada. Nesse contexto, planos de bônus formais para gestores são exemplos de criadores de incentivos para escolhas contábeis que visam ao aumento de lucro. Em companhias nas quais o pagamento do CEO é baseado em lucros contábeis, executivos têm incentivos para escolher aumentar lucros por meio de métodos contábeis.

Christie e Zimmerman (1994) estudaram se ex ante às F\&A as companhias que subsequentemente se tornam alvos contêm mais propensão à maximização de valor que outras que não foram alvos. Foi encontrado que ex ante as F\&A gestores selecionam mais procedimentos contábeis de aumento de lucro do que naquelas que não foram companhias-alvo.

Nessa categoria analítica, Chiu, Teoh e Tian (2013) testaram se o EM se "espalha" entre as empresas por meio do compartilhamento de membros do conselho administrativo (shared board of directors). 
Ficou descoberto que uma companhia tem maior probabilidade de EM quando compartilha um diretor comum com outra que atualmente gerencia resultados; e é menos provável que ocorra EM quando há compartilhamento de diretores comuns com diretores não manipuladores de resultados.

Chiu, Teoh e Tian (2013) expõem que o contágio do EM é mais forte quando o membro compartilhado tem uma posição de liderança ou de relevância contábil (por exemplo, presidente ou membro da comissão de auditoria) em seu conselho ou no conselho da empresa "contagiosa". Essas conclusões apoiam a opinião de que o monitoramento do conselho de administração desempenha um papel fundamental no contágio e na qualidade dos relatórios financeiros das empresas.

Em outro estudo, Fich, Rice e Tran (2016) verificaram se o bônus pago pela ocorrência da F\&A aos CEOs da firma target facilitam a transferência de riqueza dos acionistas da companhia-alvo para os da adquirente. Para esses autores, quando os CEOs da companhia-alvo recebem bônus pela $\mathrm{F} \& \mathrm{~A}$, os adquirentes pagam prêmios mais baixos, mas também recebem menos pela sinergia gerada com a transação. Além disso, ambos os retornos contábeis e das ações para as companhias adquirentes são mais baixos em acordos com os CEOs da target recebendo bônus. Fich, Rice e Tran (2016) indicam que, em F\&A com baixa sinergia, o bônus pela operação desempenha papel econômico importante, proporcionando um ajuste necessário na remuneração recebida pelos CEOs relacionada à $\mathrm{F} \& \mathrm{~A}$, alinhando seus incentivos com os de seus acionistas.

Quando Fich, Rice e Tran (2016) isolaram situações que podem envolver sérios problemas de agência, as transferências de riqueza parecem ocorrer em F\&A com pagamento de bônus em que companhias-alvo apresentam anormalidades contábeis. Especificamente, a riqueza parece ser transferida da companhia-alvo para os acionistas adquirentes quando uma companhia-alvo, com pagamento de bônus, tem accruals anormais persistentemente altos ou está sujeita a uma ação de execução da Security Exchange Commission (SEC). Mesmo assim, para os autores, os resultados indicam que maiores pacotes de remuneração dos executivos e até pagamentos paralelos - particularmente quando os pagamentos aos acionistas 
são baixos - não representam necessariamente comportamentos administrativos "nefastos" e podem ter consequências produtivas ao encorajar acordos favoráveis.

Wang, Xie e Zhu (2015) também contribuíram para o escopo dessa categoria analítica. Exploraram se a experiência de diretores independentes afeta a efetividade do monitoramento do conselho e descobriram que a presença deles no comitê de auditoria e com experiência na indústria a qual a companhia pertence reduz significativamente o EM por accruals anormais. Além disso, maior representação de diretores independentes no comitê de remuneração da companhia com experiência na indústria diminui a remuneração excessiva do CEO, assim como maior presença de tais diretores em todo o conselho aumenta a sensibilidade ao desempenho do CEO e melhora os retornos da adquirente.

\subsubsection{Normas Contábeis, EM e F\&A}

AbuGhazaleh, Al-Hares e Roberts (2011) e Giner e Pardo (2015) examinaram o uso de discricionariedade pelos gestores na determinação de perdas por redução ao valor recuperável do goodwill (goodwill impairment losses) após a adoção obrigatória da International Financial Reporting Standard 3 (IFRS 3). Para os autores, embora a IFRS 3 tenha sido emitida para melhorar o tratamento contábil do goodwill, fornecendo aos usuários informações mais úteis e relevantes sobre o seu valor econômico subjacente, esta tem sido criticada com base na discricionariedade gerencial inerente ao impairment test do goodwill.

AbuGhazaleh, Al-Hares e Roberts (2011) revelam que os gestores exercem discricionariedade no reporte das perdas por redução ao valor recuperável do goodwill após a adoção da IFRS 3, especificamente em casos associados às recentes mudanças de CEO, ao alisamento de resultados (income smoothing) ${ }^{4}$ e ao big bath ${ }^{5}$. Giner e Pardo (2015)

\footnotetext{
4 "Gerenciamento" dos resultados contábeis para reduzir a variabilidade (Income Smoothing). O propósito é manter os resultados em determinado patamar e evitar sua excessiva flutuação (MARTINEZ, 2001, p. 43).

5 "Gerenciamento" dos resultados contábeis para reduzir lucros correntes em prol de lucros futuros (Take a Bath ou Big Bath Accounting). As empresas gerenciam seus resultados correntes piorando-os, tendo como propósito ter melhores resultados no futuro (MARTINEZ, 2001, p. 43).
} 
também encontraram resultados semelhantes, esclarecendo que os gestores exercem discricionariedade na notificação do goodwill impairment losses, e estratégias de big bath e smoothing estão influenciando a tomada de decisões dos gestores em F\&A. Conforme esses autores, o tamanho da companhia é um atributo significativo na análise, sugerindo que o custo e a complexidade da execução do impairment test afetam as decisões dos gestores (GINER; PARDO, 2015).

Apesar disso, AbuGhazaleh, Al-Hares e Roberts (2011) mostram que os resultados também revelam que goodwill impairments losses estão fortemente associados aos efetivos mecanismos de governança, sendo provável que estes, quando eficazes, restringem a capacidade dos gestores de reportar goodwill impairment losses que diferem das perdas econômicas previstas, resultando no reconhecimento de impairment mais oportuno e que melhor reflita os fatores econômicos subjacente da empresa.

Caruso, Ferrari e Pisano (2016) também estudaram aspectos voltados ao goodwill em empresas participantes de F\&A. O objetivo foi entender se o comportamento gerencial na redução do goodwill, decorrente da F\&A, mudou após a adoção das IAS/IFRS, buscando evidências de práticas de EM. Para esses autores, as evidências parecem provar que as empresas adquirentes tendem a adotar vários instrumentos para determinar o valor adequado do goodwill gerado pela companhia-alvo, inclusive as práticas complexas de EM. Eles ressaltam que o goodwill pode ser usado para o Real Earnings $\mathrm{Ma-}$ nagement - REM e/ou EM por accruals discricionários.

Caruso, Ferrari e Pisano (2016) mostram que o goodwill apresenta impacto substancial sobre os lucros e valor da ação. Tal impacto é particularmente relevante quando se consideram as diferentes regras de divulgação definidas pelas IAS/IFRS. Os resultados identificados por eles não provam certas práticas EM, mas destacam muito claramente que, após a adoção das IAS/IFRS, o comportamento dos gestores mudou profundamente. Quanto à prática de EM que é mais utilizada, os autores alegam que a amostra limitada não permite generalização, mas não há escolha unívoca - foram encontrados casos de income smoothing, bem como big bath, quase igualmente distribuídos. Isto mostra que cada firma segue a própria "estratégia de EM" (CARUSO; FERRARI; PISANO, 2016). 
Ainda no contexto das normas contábeis, EM e F\&A, o estudo de Amel-Zadeh, Meeks e Meeks (2016) comparou os diferentes regimes de contabilidade em F\&A que têm sido experimentados ao longo do tempo. Os autores identificaram que historicamente tem aumentado a probabilidade de que o valor do goodwill adquirido, em termos absolutos e relativos, diminui após a F\&A. Para Amel-Zadeh, Meeks e Meeks (2016), as normas contábeis em vigor induzem ao súbito reconhecimento de ativos intangíveis no balanço do adquirente que foram excluídos da companhia-alvo; e o investimento em intangíveis tem crescido mais rapidamente do que o investimento em bens tangíveis.

Diante dos resultados encontrados, percebe-se que as empresas adquirentes podem ser seduzidas ao EM e, por conseguinte, o valor atribuído ao goodwill adquirido não será mantido em anos pós-F\&A. Essa pressão decrescente sobre o valor do goodwill adquirido será reforçada se a sinergia esperada do negócio não for atingida, como a evidência histórica sugere que frequentemente tem sido, de acordo com Amel-Zadeh, Meeks e Meeks (2016).

\subsubsection{F\&A stock-for-stock e EM}

Conforme ressaltam Erickson e Wang (1999), em muitas operações de F\&A a companhia adquirente compra a companhia-alvo com pagamento por meio de suas ações (F\&A stock-for-stock). Ao contrário de acordos com utilização de caixa, nas transações que envolvem ações o valor recebido pelos shareholders é contingente ao valor de mercado da companhia adquirente. Quando a transação é completada, os shareholders da companhia-alvo recebem um número específico de ações da companhia adquirente para cada uma de suas ações possuídas na companhia-alvo. O número de ações da companhia adquirente trocadas para cada ação da companhia-alvo é então determinado pelo preço das ações da firma adquirente quando o acordo da F\&A for fechado, dado o preço acordado de compra da companhia-alvo. Como resultado, quanto mais elevado o preço das ações da companhia adquirente na data do contrato, menor o número de ações que devem ser emitidas para comprar a companhia-alvo.

Na visão de Botsari e Meeks (2008) em F\&A stock-for-stock, a relação de troca de ações é inversamente relacionada ao preço das 
ações da empresa adquirente; logo, quem adquire pode ter um incentivo para elevar os ganhos contábeis anteriores à aquisição na esperança de aumentar o preço de suas ações no mercado e, portanto, reduzir o custo de comprar a companhia-alvo. Consequentemente, elevar o preço de mercado das ações de uma adquirente por meio de EM é fator dependente do nível de eficiência da informação no mercado e, também, se os analistas podem constatar ou não a realização de EM empregado pelos diretores da companhia adquirente, consoante o que afirmam Botsari e Meeks (2008).

Diante o exposto, nesse tópico serão evidenciadas algumas características desse tipo de financiamento em transações de F\&A e suas inter-relações com o EM.

\subsubsection{F\&A stock-for-stock entre companhias independentes}

Na visão de Erickson e Wang (1999) as operações de F\&A são estímulos para atitudes oportunistas de EM. O trabalho desses autores objetivou investigar se companhias adquirentes tentam aumentar o preço de suas ações ex ante às operações de $\mathrm{F} \& \mathrm{~A}$. O foco central da pesquisa foi verificar se os acordos de F\&A - realizados na forma de stock-for-stock - estimulam o EM a fim de reduzir o custo de compra da companhia-alvo. Corroborando Erickson e Wang (1999), os achados de Higgins (2013) são consistentes e mostram que companhias adquirentes envolvidas em F\&A do tipo stock-for-stock têm incentivos para práticas de EM visando a reduzir o custo total da transação. Higgins (2013) examinou o comportamento de EM dos adquirentes em F\&A japonesas e constatou que essas companhias têm accruals anormais de longo prazo (especificamente depreciação, amortização, itens não operacionais e itens extraordinários) positivos ao longo do ano anterior ao anúncio da F\&A.

Seguindo a mesma linha de pensamento, o estudo de Louis (2004) avaliou a eficiência de mercado quando há EM nos relatórios contábeis em F\&A realizadas na forma stock-for-stock. Louis (2004) buscou evidenciar que, devido ao EM, as transações de F\&A apresentam baixo desempenho após a realização dos acordos. Há fortes evidências de que as companhias adquirentes superestimam os lucros no trimestre que precede o anúncio de F\&A stock-for-stock. Os resultados sugerem que o baixo desempenho das companhias 
adquirentes ex post às F\&A é parcialmente atribuído à reversão de preços dado pelo EM. Para Louis (2004), a reversão dos efeitos do EM ex ante é um determinante significativo de ambos os desempenhos - curto e longo prazo - das companhias que se engajam em F\&A stock-for-stock.

Louis (2004) constatou que F\&A stock-for-stock apresentam desempenho pior que aquelas realizadas por meio de caixa ao longo dos três anos subsequentes ao anúncio. Há correlação negativa entre accruals anormais e o desempenho no longo prazo das ações de companhias que realizaram F\&A stock-for-stock. A reversão dos efeitos do EM ex ante às F\&A stock-for-stock não é totalmente antecipada pelos analistas financeiros.

As conclusões de Louis (2004) também são confirmadas por Lee et al. (2008), ficando entendido que há um efeito negativo na riqueza em curto prazo ao longo dos dias em torno dos anúncios de F\&A stock-for-stock, e essa riqueza tem relação inversa com o EM. A pesquisa de Lee et al. (2008) investigou se as adquirentes de empresas de telecomunicações gerenciaram resultados por meio de accruals discricionários antes do anúncio da F\&A stock-for-stock; os resultados mostram que as adquirentes gerenciam os resultados para cima visando ao aumento do lucro.

Em anos posteriores, Louis (2013) continuou o estudo das relações entre EM e F\&A stock-for-stock, no entanto analisou o desempenho das ações dos adquirentes, os accruals anormais, os ativos operacionais líquidos e o uso de informações privilegiadas de adquirentes de companhias-alvos listadas e não listadas em bolsa de valores. O autor constatou que os adquirentes stock-for-stock de companhias-alvo não listadas experimentam retornos anormais negativos em cada um dos 24 meses após o mês do anúncio da F\&A. Os potenciais indicadores de sobrevalorização pré-anúncio da F\&A - razão book-to-market, accruals anormais, ativos operacionais líquidos e informações privilegiadas - também são consistentes com a noção de que os adquirentes stock-for-stock de companhias-alvo não listadas estão mais sobrevalorizados do que os de companhias-alvo listadas.

Em recente pesquisa, Louis e Sun (2016) examinaram o comportamento oportunista dos gestores de companhias adquirentes na geração de relatórios contábeis em volta de anúncios e efetivação de 
F\&A stock-for-stock, analisando a associação entre o cronograma dos anúncios e o comportamento dos gestores refletido nesses relatórios. Os autores mostraram que a associação negativa entre o desempenho de mercado pós-anúncio da F\&A e os accruals anormais pré-anúncio é substancialmente mais forte para os anunciantes de sextas-feiras do que para os anunciantes não sexta-feira. Além disso, verificaram que o efeito sexta-feira é impulsionado em grande parte por F\&A que são concluídas no dia do anúncio ou dentro das primeiras dez semanas (70 dias) após o anúncio.

Para Louis e Sun (2016), os adquirentes stock-for-stock que gerenciam seus resultados pré-anúncios de uma $\mathrm{F} \& \mathrm{~A}$ tendem não apenas a fazer anúncios quando os investidores estão menos atentos, mas também a distanciar suas atividades de EM da data do anúncio da F\&A. Os autores acrescentam que, embora a hipótese de EM seja plausível, ela não explica por que os investidores não conseguem captar plenamente a informação e os sinais públicos em suas reações aos anúncios de F\&A. As evidências sugerem que a inatenção do investidor e o calendário estratégico dos anúncios e efetivação de eventos corporativos são potenciais razões pelas quais os investidores aparentemente não conseguem corrigir totalmente o EM (LOUIS; SUN, 2016).

Contrariando os resultados precedentes, Heron e Lie (2002) não encontraram evidências de que adquirentes gerenciam seus resultados antes de $\mathrm{F} \& \mathrm{~A}$, apesar de existirem incentivos em planos de F\&A stock-for-stock. Verificou-se que, ex ante às F\&A, companhias adquirentes exibem níveis de desempenho operacional que excedem aquelas de seus respectivos setores; após a F\&A essas companhias continuam exibindo os mesmos níveis de desempenho. Apesar desses resultados, quando Heron e Lie (2002) categorizaram a amostra de acordo com o tipo de pagamento, foram encontradas diferenças nos accruals discricionários ex ante ou ex post às F\&A. Também ficou constatada melhoria no desempenho operacional subsequente quando companhias com alto market-to-book adquirem companhias com baixo market-to-book e quando a adquirente e companhia-alvo pertencem ao mesmo setor.

Botsari e Meeks (2008) sugerem que companhias adquirentes se engajam em manipulação de accruals para aumento de lucros 
no ano anterior ao anúncio da oferta e que essa manipulação está, na maioria das vezes, concentrada no componente dos accruals de capital de giro. Soma-se que o EM dos adquirentes está associado aos ganhos anormais no preço das ações nos dois anos à frente da aquisição. Há também evidências de reversão dos accruals no período imediatamente após a conclusão das F\&A, que, no entanto, tornam-se menos articulados quando uma medida baseada em fluxo de caixa é adotada (nesse caso os accruals discricionários são negativos, mas não estatisticamente significativos). Uma possível interpretação dessa discrepância é que os accruals discricionários negativos observados sob o enfoque do balanço patrimonial refletem o impacto que as F\&A têm no balanço; impacto que é menos óbvio quando uma medida "mais limpa" é usada - EM por decisões operacionais baseadas no fluxo de caixa.

Nesse contexto, Zhang (2015) analisou se as empresas adquirentes tentam adotar estratégia de EM por decisões operacionais (Real Earnings Management - REM) para elevar os lucros no período de anúncio das F\&A. Além disso, o autor também procurou fornecer uma explicação para o baixo desempenho pós-F\&A stock-for-stock. Utilizando a metodologia proposta por Roychowdhury (2006) para medir a magnitude do REM, apontou que as empresas que utilizam ações como meio de financiamento em F\&A apresentam fluxos de caixa anormais negativos e despesas discricionárias anormais negativas, mas custos de produção anormais significativamente positivos durante o período corrente da F\&A (ZHANG, 2015). Os resultados apontam que as empresas adquirentes usam o REM para aumentar os lucros objetivando melhorar a confiança do mercado; também há uma associação negativa entre o REM e o baixo desempenho pós-F\&A.

Concluindo, Baik et al. (2015) examinaram os efeitos dos ambientes institucionais das companhias-alvo no comportamento do EM das compradoras em torno de F\&A stock-for-stock cross-border. Para os autores, o fato de o adquirente se engajar ou não no EM difere devido ao nível de incerteza resultante dos ambientes institucionais da companhia-alvo como língua, cultura, religião, qualidade dos padrões contábeis e ambientes políticos e legais.

Baik et al. (2015) verificaram que o comportamento de EM torna-se mais evidente quando são adquiridas companhias-alvo de 
países com maiores diferenças institucionais, como não cristãos, aqueles com baixo nível de estabilidade política, com baixo nível de democracia e da liberdade de imprensa e de mídia, com alta corrupção e com baixo nível de eficácia governamental. Em geral, esses resultados sugerem que o adquirente se envolve em para diminuir o risco de pagamento excessivo decorrente da incerteza causada por diferenças institucionais, reduzindo assim o custo global da F\&A. O adquirente geralmente tem um incentivo para se envolver em EM como um meio para compensar o aumento do custo decorrente da incerteza sobre o contrato.

\subsubsection{F\&A stock-for-stock entre companhias associadas}

Diferentemente de outros autores, Jeong e Bae (2013) estudaram as F\&A stock-for-stock entre empresas pertencentes ao mesmo grupo empresarial. Nesse tipo de transação, as participações do proprietário controlador na adquirente e na companhia-alvo cria um forte incentivo para que o proprietário controlador intencionalmente pague mais pela companhia-alvo do que ela realmente vale.

Diante disso, Jeong e Bae (2013) constataram que as adquirentes "esvaziam" os lucros a fim de aumentar o número de ações a serem emitidas aos acionistas da companhia-alvo. Outro aspecto encontrado é que a reação do preço das ações aos anúncios das F\&A entre empresas associadas está negativamente correlacionada com a diminuição dos lucros do período anterior ao anúncio. Os resultados mostram que o desempenho pós-F\&A de empresas associadas é inferior ao das F\&A de empresas independentes.

Por fim, Jeong e Bae (2013) mostram que o desempenho dos preços no longo prazo, pós-F\&A entre companhias associadas listadas em bolsas de valores, é consideravelmente mais baixo do que nas F\&A entre companhias independentes, ou em F\&A de companhias associadas que não são listadas em bolsas de valores.

\subsubsection{F\&A stock-for-stock e desdobramento de ações}

Outro estudo voltado às F\&A stock-for-stock foi documentado por Guo, Liu e Song (2008). Esses autores encontraram que as empresas adquirentes têm mais probabilidade de desdobrar suas 
ações (split de ações) antes de fazer anúncios de F\&A do que as não adquirentes, especialmente quando se trata de F\&A stock-for-stock.

Usando a qualidade dos lucros como uma proxy para a intenção das empresas em manipular resultados, Guo, Liu e Song (2008) descobriram que os adquirentes com baixa qualidade de lucros (ou seja, compradores mais propensos a usar divisões de ações para manipular seus valores de ações) têm retornos das ações no longo prazo mais baixos comparado com seus benchmarks. Em contraste, aqueles com alta qualidade de lucros não mostram esse padrão.

Conforme Guo, Liu e Song (2008), o split de ações pode ser usado como ferramenta de manipulação, além de outros meios de manipulação de preços, como o EM. As companhias-alvo devem considerar essas informações para discernir entre os adquirentes - se eles recentemente realizaram um split de ações e o quão altos são seus accruals discricionários, garantindo que os preços das ações não estejam sendo manipulados e que as trocas se realizem de forma justa.

\subsubsection{F\&A stock-for-stock e governança corporativa}

Lehmann (2016) investigou o papel da governança corporativa no EM por accruals antes de F\&A stock-for-stock. Em contraste com as alegações comuns de que governança corporativa forte restringe o EM por accruals, Lehmann (2016) mostra que os adquirentes com forte governança se envolvem mais agressivamente na manipulação para aumento de lucro do que aqueles com fraca governança. Os resultados são robustos aos diferentes modelos de accruals discricionários, às diferenças na estrutura de crescimento da empresa, às variáveis de controle, a um grupo de controle de $100 \%$ de adquirentes por meio de caixa, aos retornos anormais de longo prazo (buy-and-hold) e a possíveis problemas de seleção amostral.

Lehmann (2016) esclarece que outras formas de EM (por exemplo, REM) podem tornar-se mais importantes no longo prazo como substitutos do EM baseado em accruals. Para esse autor, futuras pesquisas poderiam abordar F\&A relacionadas com determinantes da manipulação de accruals em mais detalhes para obter compreensões mais abrangentes dos incentivos econômicos subjacentes ao EM antes de F\&A stock-for-stock. 


\subsubsection{F\&A stock-for-stock e ações judiciais}

Gong, Louis e Sun (2008) alegam que, devido ao fato de as companhias adquirentes se sujeitarem a processos judiciais, o EM ex ante às $\mathrm{F} \& \mathrm{~A}$ pode ter um efeito indireto no desempenho dessas companhias em torno e após o anúncio das F\&A; tal efeito será diretamente proporcional aos efeitos associados à reversão dos accruals ex post. A pesquisa constatou que há uma associação positiva entre os accruals anormais ex ante F\&A e os anúncios de ações judiciais ex post naquelas transações stock-for-stock. Notou-se que o mercado antecipa - no momento do anúncio da F\&A - apenas parcialmente os efeitos de ações judiciais ex post às F\&A. Gong, Louis e Sun (2008) encontraram que há associação negativa entre o anúncio de retornos anormais no longo prazo - pós-F\&A - e a probabilidade de uma ação judicial ocorrer pós-F\&A. Além disso, o mercado provavelmente subestima as perdas contingentes associadas com F\&A stock-for-stock.

Para Gong, Louis e Sun (2008), as ações judiciais não somente são associadas ao baixo desempenho pós-F\&A, mas também representam provavelmente um direcionador desse baixo desempenho. Esse resultado é muito importante, dados a natureza enigmática do fraco desempenho pós-F\&A e o maior interesse em explicar esse fenômeno.

\subsubsection{F\&A stock-for-stock e procura por compradores}

Anagnostopoulou e Tsekrekos (2013) examinaram se as conclusões relacionadas ao EM - com base em accrual - para companhias de capital aberto que procuram por compradores (seeking a buyer) podem ser extrapoladas fora do contexto dos EUA, uma vez que pesquisas anteriores indicaram que a F\&A é altamente dependente do grau de competição de um país. Os testes para a existência de EM foram realizados em companhias listadas nas maiores bolsas europeias entre 2000 e 2009.

Anagnostopoulou e Tsekrekos (2013) alcançaram evidências da ocorrência de EM para diminuir lucros em torno dos anúncios seeking a buyer, sendo mais forte para o país com mercado mais competitivo de controle corporativo - nesse caso, o Reino Unido. De acordo com os autores, os achados indicam que ambientes competitivos de F\&A podem induzir comportamentos de EM, e este afeta positivamente os retornos anormais em torno dos anúncios seeking a buyer. Em ou- 
tras palavras, a presença de um ambiente de F\&A competitivo pode servir como gatilho para o EM, que é observado entre companhias seeking a buyer em ambientes mais competitivos, como os EUA e o Reino Unido, mas não para mercados com menor concorrência.

Em outro estudo, Anagnostopoulou e Tsekrekos (2015) fornecem evidências de EM para diminuir lucro em companhias-alvo que anunciaram publicamente a intenção de ser adquiridas. Usando todas as companhias não financeiras listadas nos EUA que anunciaram publicamente a intenção de ser adquiridas entre 1990 e 2012, notou-se que estas tendem a ser mais alavancadas do que as companhias correspondentes de tamanho equivalente na mesma indústria, apresentam menor liquidez e crescimento e também tendem a ser ligeiramente piores em desempenho.

Para Anagnostopoulou e Tsekrekos (2015) as companhias que procuram por compradores se engajam em EM, reduzindo os lucros em até dois anos antes do evento e também no ano do evento. Esse achado pode ser interpretado de maneiras alternativas: sugere o possível esforço para que essas companhias se tornem alvos mais atraentes em termos de preço, uma vez que podem antecipar que seu curso futuro poderia ser melhorado ao encontrar um adquirente; ou indicar sua intenção de reconhecer todos os possíveis problemas que tiveram até o evento. Conforme os autores, esse comportamento permitiria à companhia fazer um novo começo, limpar as demonstrações financeiras antes de procurar ativamente um comprador. As companhias menos lucrativas, de menor crescimento e mais financeiramente "angustiadas" são consideradas mais propensas a esse comportamento de EM.

Ao dividir as companhias em adquiridas e não adquiridas, Anagnostopoulou e Tsekrekos (2015) observaram que a reação do mercado é significativamente positiva apenas para aquelas que não gerenciaram resultados para assegurar uma aquisição ao longo de dois anos após o anúncio. Os autores também encontraram que as companhias adquiridas dentro de um período razoável após o anúncio foram aquelas que não apresentam comportamento de EM. Os potenciais compradores têm preferência por companhias que não praticam EM. 
Campa e Hajbaba (2016) também estudaram o comportamento oportunista de companhias-alvo, investigando se o retorno anormal da adquirente pós-F\&A é atribuído ao REM e/ou EM por accruals da companhia-alvo. Os resultados indicaram que as companhias-alvo praticam REM manipulando as vendas - em vez de manipulações por accruals - para elevar lucros ao longo do ano anterior às F\&A. Foram encontradas evidências de associação entre o método de financiamento em F\&A e EM nas companhias-alvo, o que poderia impactar o desempenho das adquirentes pós-F\&A.

Para Campa e Hajbaba (2016), o comportamento de manipulação de vendas é restrito às companhias-alvo envolvidas em F\&A financiadas por caixa e que, em tal cenário, também afeta negativamente o desempenho anormal de longo prazo dos adquirentes. Além disso, as companhias manipulam lucros usando a abordagem que é mais adequada, dependendo de cada situação específica. Segundo Campa e Hajbaba (2016), uma vez que o EM por accruals é facilmente detectável pelo processo de due diligence que as companhias-alvo passam antes de F\&A, essas empresas tendem a manipular os resultados por meio do REM.

\subsubsection{F\&A stock-for-stock e disclosure voluntário}

Kimbrough e Louis (2011) pesquisaram os fatores que influenciam o disclosure voluntário por adquirentes em momentos do anúncio de F\&A. Com base em uma análise de conteúdo de uma amostra de adquirentes stock-for-stock, os autores fornecem evidências de que o maior volume de informações fornecidas nas conference calls (teleconferências) em relação aos comunicados à imprensa, bem como a maior ênfase nos detalhes prospectivos nas conference calls em relação aos comunicados à imprensa, contribuem para retornos mais favoráveis aos anúncios de F\&A. Verificou-se que os adquirentes são mais propensos a manter conference calls para anunciar F\&A stock-for-stock.

Kimbrough e Louis (2011) descobriram que a reação do mercado aos anúncios de F\&A por conference calls simultâneas é mais favorável do que aos anúncios em que os adquirentes dependem exclusivamente de comunicados da imprensa. Embora esperado, Kimbrough e Louis (2011) não encontraram nenhuma evidência de 
que os retornos superiores anunciados subsequentemente se revertem ou que as conference calls estão associadas a accruals anormais pré-anúncio.

Em geral, o estudo demonstra que os adquirentes utilizam divulgação suplementar no momento do anúncio da F\&A como meio para influenciar positivamente os preços das ações. Mais importante ainda: a análise sugere que os gerentes usam conference calls em anúncios de F\&A como meio de transmitir informações privadas genuínas em vez de fazer propagandas falsas sobre os preços de suas ações.

\subsubsection{F\&A e erros na estimação do EM}

A pesquisa de Hribar e Collins (2002) examinou o impacto de calcular os accruals a partir da mudança em sucessivas contas do balanço patrimonial de companhias abertas, em vez de calculá-los diretamente pela demonstração dos fluxos de caixa. Foi avaliado o erro introduzido pela abordagem indireta de estimação dos accruals a partir do balanço patrimonial para demonstrar as implicações nos estudos que têm se baseado nessa abordagem.

Para Hribar e Collins (2002), os erros na estimação dos accruals pelo balanço patrimonial podem confundir os resultados das regressões que utilizam accruals discricionários e não discricionários como variáveis explicativas. Os autores evidenciaram que, quando a estimação dos accruals pelo balanço patrimonial é usada como variável independente numa regressão de retornos em relação aos componentes do lucro, ocorrem erros de estimação dos parâmetros. Quando eventos significativos, tais como F\&A e operações descontinuadas, estão ausentes nas análises, o erro resultante das estimativas dos accruals é bastante baixo.

No que tange às F\&A, Hribar e Collins (2002) encontraram evidências significativas de aumentos no lucro a partir de operações de EM quando se utilizam accruals do balanço patrimonial. No entanto, para a mesma distribuição usando accruals estimados a partir da demonstração de fluxo de caixa não foram evidenciadas atividades de EM. Na visão desses autores, o erro nos accruals totais e os resultados enviesados dos coeficientes das regressões poderão 
levar os pesquisadores a concluírem que existe EM quando na verdade não há.

A pesquisa de Hribar e Collins (2002) demonstra que podem ser substanciais a frequência e a magnitude dos erros introduzidos nas análises de EM quando são usados accruals estimados a partir do balanço patrimonial. Portanto, torna-se interessante que os estudos que utilizaram tal abordagem sejam reavaliados à luz do potencial impacto do erro na estimação dos accruals.

\subsubsection{Qualidade da auditoria, F\&A e EM}

Com foco nas companhias listadas no Reino Unido auditadas por empresas de auditoria Big-X (Ernst \& Young, Deloitte, KPMG e Arthur Anderson) e não-Big-X antes e depois da F\&A da PricewaterhouseCoopers em 1998, Ding e Jia (2012) concluíram que a qualidade da auditoria (medida pela qualidade dos lucros dos clientes auditados) melhorou no período pós-F\&A, uma vez que, em comparação com os clientes de empresas não-Big- $X$, os accruals discricionários absolutos de clientes das Big- $X$ diminuíram no período pós-F\&A.

No período pós-F\&A, Ding e Jia (2012) encontraram que os lucros dos clientes das Big-X estão mais relacionados aos retornos do mercado de ações, o que implica que os investidores percebem a value relevance dos lucros. Em contraste, não foi encontrada essa característica para empresas clientes de não-Big-X.

Outro achado foi a evidência de que ocorreu aumento significativo nos honorários de auditoria para os clientes das Big-X no período pós-F\&A. No entanto, não há nenhuma diferença significativa entre os honorários de auditoria cobrados pelos auditores não-Big-X em períodos anteriores e pós-F\&A. Os resultados sugerem que as economias de custos decorrentes de uma F\&A (que tendem a reduzir os honorários de auditoria) são dominadas por um poder de mercado coletivamente melhorado dos auditores de "alto nível" (que tendem a aumentar os honorários de auditoria). Além disso, uma fusão entre auditores de "alto nível" também pode ajudar a posição de auditores de "segunda linha", pois eles podem usar preços competitivos para desafiar seus grandes rivais. 
Seguindo essa linha, Wang, Liu e Chang (2011) utilizaram a F\&A da Diwan, Ernst \& Young e J.T. Lai \& Co. para estudar os efeitos de uma F\&A entre empresas de contadores públicos certificados (Certified Public Accountant - CPA) sobre a qualidade da auditoria, medida por accruals discricionários.

Wang, Liu e Chang (2011) constataram que as magnitudes do aumento do tamanho e reputação causados pela F\&A são diferentes entre as duas empresas. A evidência empírica mostra que, após a F\&A, os accruals discricionários dos clientes das duas empresas diminuem significativamente. Além disso, a dimensão da alteração é maior para os clientes da J.T. Lai \& Co. do que para os da Diwan, Ernst \& Young. O tamanho da empresa de auditoria e sua reputação importam em mercados em desenvolvimento.

No que tange ao estudo de Xie, Yi e Zhang (2013), notou-se que as companhias com auditores considerados Big N (maiores empresas de auditoria do mundo) são mais propensas a se tornar alvos de F\&A e mais prováveis de ser finalmente adquiridas em negócios de F\&A. As análises sugerem que os efeitos dos auditores Big $\mathrm{N}$ da companhia-alvo sobre a probabilidade de se tornarem alvos e sobre as taxas de conclusão da F\&A são mais acentuados para as companhias com baixa qualidade de accruals (proxy para o alto risco informacional). Em geral, Xie, Yi e Zhang (2013) indicam que os auditores Big $\mathrm{N}$ da companhia-alvo facilitam as operações de F\&A, reduzindo o risco informacional de um alvo e os custos esperados de litígios.

\subsubsection{Tomada de controle e EM}

Segundo Zhao e Chen (2008), muitas companhias americanas instalaram várias defesas para a tomada de controle (takeover protection), incluindo eleições do staggered board (conselho composto por diferentes classes de diretores) para proteger os administradores encarregados e diretores externos de serem removidos pelos acionistas. Distinto de um conselho unitário em que todos os diretores se apresentam para eleição a cada ano, um staggered board classifica seus diretores em classes (tipicamente, três classes), e somente uma está para a eleição em cada assembleia anual de acionistas, conforme informam Zhao e Chen (2008). 
Combinado com poison pills, um staggered board pode tornar extremamente difícil que um adquirente encaixe uma aquisição bemsucedida. Sendo assim, Zhao e Chen (2008) examinaram a relação entre takeover protection e EM. Os resultados indicam que a takeover protection está associada a menores níveis de accruals anormais de capital de giro, níveis mais baixos de desempenho ajustado aos accruals anormais e reconhecimento tempestivo de perdas. Outros testes mostram que a takeover protection está associada com menor valor da firma, o que contradiz a Alignment Theory, mas apoia a Quiet Life Theory.

Para Zhao e Chen (2008), as evidências indicam que a takeover protection pode permitir que os gestores desfrutem do que sugere a Quiet Life Theory; portanto, não só faz a takeover protection contribuir com o valor justo das F\&A, mas também atenuar os incentivos dos gestores para a prática do EM. A redução da takeover protection pode, portanto, incentivar o aumento do EM e a redução da qualidade dos relatórios financeiros.

Em outra pesquisa, Zhao e Chen (2009) confirmam que as companhias incorporadas em estados americanos que passaram a utilizar leis de takeover protection capturam menores magnitudes de accruals anormais e maiores níveis de informatividade dos lucros nos períodos pós-passagem, sugerindo que a takeover protection mitiga o EM e melhora a qualidade dos lucros. Para os autores, um custo social em reduzir essa proteção pode levar a que a qualidade da informação financeira diminua.

Zhao et al. (2012) também examinaram se a takeover protection agrava ou mitiga o REM (ou seja, usando atividades reais anormais para atender a metas de lucros no curto prazo). Há sinalização de que a takeover protection reduz a pressão dos gestores para recorrer ao REM como um meio caro para melhorar o desempenho futuro. Essa estratégia de EM permite que os gestores atinjam metas de resultados no curto prazo, prejudicando a capacidade da empresa de gerar fluxos de caixa em períodos futuros.

Conforme Zhao et al. (2012), a takeover protection alivia as preocupações dos gestores sobre aquisições hostis e, assim, mitiga a pressão para evitar decepções nos lucros por meio do REM. Usando staggered boards como proxy primária para a takeover protection, Zhao 
et al. (2012) descobriram que as companhias com staggered boards estão associadas a níveis mais baixos de REM com a finalidade de cumprir metas de lucros.

Ainda, sobre as relações entre takeover e EM, Raman, Shivakumar e Tamayo (2013) estudaram como as decisões de takeover são influenciadas pela qualidade da informação refletida nos lucros das companhias-alvo. Os autores mostraram que as adquirentes preferem "takeovers negociadas", ou seja, aquelas em que o proponente tem acesso aos livros contábeis e a outras informações privilegiadas sobre a companhia-alvo, em acordos envolvendo companhias-alvo com baixa qualidade dos lucros. Além disso, a qualidade dos lucros e os prêmios de aquisição são negativamente relacionados em "takeovers negociadas", sugerindo que os adquirentes obtêm informação privada valiosa por meio das negociações. Os adquirentes compartilham o risco informacional com os acionistas da companhia-alvo que apresenta baixa qualidade de lucros - é utilizada maior parcela de ações como fonte de pagamento da takeover.

\subsubsection{Sarbanes-Oxley, F\&A e EM}

O estudo de Gavious e Rosenboim (2013) teve como objetivo aprofundar se e como a passagem da Lei Sarbanes-Oxley (SOX) afetou a qualidade dos lucros, tendo como proxy as medidas de accruals, antes de F\&A. Dado que os mercados de capitais sofreram alterações incomuns no período que antecedeu a passagem da SOX, Gavious e Rosenboim (2013) subdividiram o período anterior à SOX em quatro subperíodos: (1) a bolha pré-tecnologia (1992-1997); (2) a bolha tecnológica (1998-3/2000); (3) o colapso da bolha $(4 / 2000-$ 9/2001); e (4) o período do escândalo pré-SOX (10/2001-7/2002).

Gavious e Rosenboim (2013) documentaram que os accruals anormais moveram-se de positivos para negativos durante o período dos principais escândalos corporativos imediatamente anteriores à SOX e permaneceram negativos no período pós-SOX. No entanto, os accruals anormais no período pós-SOX foram menos negativos do que durante os escândalos. Para Gavious e Rosenboim (2013), a redução dos accruals anormais e o aumento da qualidade dos lucros parecem ter ocorrido concomitantemente com os escândalos, não como resultado da passagem da SOX. Eles também encontraram 
que a percepção dos investidores sobre o EM dado pelos vendedores cresceu após o estouro da bolha tecnológica, refletido no aumento do desconto aplicado aos preços das F\&A ao longo dos subperíodos.

O maior desconto aplicado após a SOX em relação àquele imediatamente anterior à SOX implicou que os investidores não dependeram da SOX para evitar as práticas de EM antes das F\&A, conforme ressaltam Gavious e Rosenboim (2013). Em vez disso, outros eventos, como o estouro da bolha tecnológica e revelações de grandes escândalos contábeis, parecem ter afetado a propensão dos gestores ao EM.

\subsubsection{Pesquisa e Desenvolvimento, F\&A e EM}

Em contraste com a hipótese de sobrevalorização da companhia -alvo, a motivação dos adquirentes para baixar valores de Pesquisa e Desenvolvimento em Processo (in-process R\&D - IPRD) poderia ser explicada pela hipótese de EM, afirmam Hsu, Kim e Song (2009). O dispêndio imediato da IPRD pelas adquirentes aumenta o lucro nos anos subsequentes porque as companhias podem evitar despesas de amortização ou impairment do goodwill. Uma vez que a R\&D adquirida é imediatamente reconhecida como despesa, as companhias podem inflar a medida de rentabilidade dos ativos (ROA) e retorno sobre o patrimônio (ROE).

Diante disso, Hsu, Kim e Song (2009) testaram a hipótese de EM investigando mudanças no ROA, ROE e retornos das ações de adquirentes após F\&A. Esses autores encontraram que as adquirentes com baixas contábeis de IPRD não apresentam ROA ou ROE mais elevado em anos subsequentes, comparativamente com aquelas companhias de mesmo tamanho e indústria. Além disso, os retornos das ações no longo prazo de um a três anos após a F\&A não são estatisticamente diferentes quando comparados com as empresas benchmark.

Outros resultados mostram que as empresas que adquirem alvos com maiores investimentos em R\&D tendem a baixar alguns dos ativos de R\&D adquiridos após a conclusão da F\&A. Constatou-se também que o retorno anormal acumulado mediano durante os três dias em torno dos anúncios de F\&A, para adquirentes com baixas subsequentes em IPRD, é de $-2,73 \%$, ao passo que para os adquirentes sem baixas de IPRD é de - $0,60 \%$. De acordo com Hsu, Kim e 
Song (2009), isso sugere que os retornos das ações dos adquirentes em torno de anúncios de F\&A são muito menores quando os investidores esperam que os adquirentes custeiem o IPRD. Também ficou constatado que as baixas em IPRD não aumentam os lucros ou os retornos das ações dos adquirentes após as F\&A, o que é inconsistente com a hipótese de EM.

\subsubsection{Diversificação geográfica e industrial, $F \& A$ e EM}

Vasilescu e Millo (2016) investigaram se a diversificação por F\&A tem impacto sobre o EM por accruals realizado pelas companhias-alvo do Reino Unido. Foram diferenciados dois tipos de diversificação: industrial e geográfica. Para Vasilescu e Millo (2016), essas duas dimensões de diversificação diferem quanto ao grau de assimetria informacional: em companhias diversificadas industrialmente os accruals ao nível do segmento de negócios tendem a se compensar um ao outro, ao passo que as geograficamente diversificadas parecem estar sujeitas a maior assimetria informacional.

A diversificação industrial mitiga o EM dado pelas companhias -alvo do Reino Unido antes de F\&A. Aliás, uma combinação de diversificação industrial e geográfica está associada ao menor grau de EM. Já a diversificação geográfica está associada a maior grau de EM, no entanto os resultados não são estatisticamente significativos.

Ainda, Vasilescu e Millo (2016) verificaram que, em comparação com as companhias do mesmo segmento, as industrialmente diversificadas têm menor grau de EM, independentemente de operarem apenas no mercado interno ou em diferentes regiões geográficas. A análise não descartou a possibilidade de que exista maior incentivo para manipular os lucros em empresas industrialmente diversificadas, mas apenas que há provas estatisticamente significativas de que essas tentativas são feitas com menos frequência.

\subsubsection{Cobertura dos analistas, F\&A e EM}

Irani e Oesch (2013) e Irani e Oesch (2016) propuseram pesquisar como os analistas de valores mobiliários influenciam os gestores no uso de diferentes tipos de EM. Foram empregados, respectivamente, um experimento natural e um quasi-experimento para explorar as reduções exógenas na cobertura do analista resultante de F\&A de corretoras. 
Observou-se que os gestores respondem à perda de cobertura dos analistas, decrescendo a manipulação por REM enquanto aumentam a manipulação por uso de EM baseado em accruals. Esses efeitos são significativamente mais fortes entre as empresas com menor cobertura e para aquelas próximas ao limiar de lucro zero. As evidências sugerem que os gestores usam o REM para melhorar o desempenho no curto prazo em resposta à pressão do analista, efeitos que não são descobertos quando se focam unicamente os métodos baseados em accruals.

Irani e Oesch (2016) ressaltam que, uma vez que a cobertura do analista e as decisões de conclusão da F\&A correlacionam-se com as características da companhia por inúmeras razões, as estimativas encontradas nos estudos existentes tendem a ser tendenciosas devido à endogeneidade. $\mathrm{O}$ experimento natural e o quasi-experimento utilizado nos dois estudos abordam esse problema de identificação focando um grande conjunto de reduções de cobertura, presentes ao longo de toda a série de tempo e corte transversal das companhias.

\section{CONSIDERAÇõeS FINAIS}

Analisar as transações que abarcam as F\&A ex ante e ex post aos eventos deliberativos, anúncios e efetivação de contratos pode trazer resultados interessantes para os acionistas, empresas proponentes, empresas-alvo e investidores em geral, os quais podem avaliar melhor a magnitude dos retornos obtidos e a extensão de sua variabilidade, detectando com antecedência ações oportunistas e discricionárias dos gestores. Assim, o presente trabalho procurou levantar as produções mais relevantes sobre EM operações de F\&A. Considerando a importância das F\&A no cenário mundial buscou-se responder como se encontra o estado da arte das pesquisas que relacionam o earnings management com as transações de F\&A.

Os principais resultados apontaram que diversos pesquisadores se preocupam com a evidenciação dos motivos que levam as companhias a se engajarem em operações oportunistas de EM, principalmente quando o EM é voltado para manipulação dos accruals no sentido de elevar o lucro em períodos que antecedem as F\&A. Além disso, algumas pesquisas introduziram a importância de verificar a manipulação de resultados por meio do REM. 
As análises também indicaram que planos de bônus formais para gestores são exemplos de criadores de incentivos para escolhas contábeis que visam ao aumento de lucro. Em companhias adquirentes nas quais o pagamento do CEO é baseado em lucros, executivos têm incentivos para escolher aumentar lucros por meio de métodos contábeis. Na mesma linha, quando os CEOs da companhia-alvo recebem bônus pela F\&A os adquirentes pagam prêmios mais baixos.

Ressalta-se que uma companhia tem maior probabilidade de se engajar em operações de EM quando compartilha um diretor comum com outra que atualmente gerencia resultados; e é menos provável que ocorra EM quando há compartilhamento de diretores comuns com aqueles não manipuladores de resultados. A presença de diretores independentes no comitê de auditoria e com experiência no setor da companhia reduz o EM por accruals anormais. Aliás, maior representação de diretores independentes no comitê de remuneração da companhia com experiência no setor poderá reduzir a remuneração excessiva do CEO.

No que tange às normas contábeis e suas relações com o EM e $\mathrm{F} \& \mathrm{~A}$, os resultados revelaram que gestores podem exercer discricionariedade no reporte das perdas por redução ao valor recuperável do goodwill após a adoção da IFRS 3, especificamente em casos associados às recentes mudanças de CEO, ao alisamento de resultados e ao big bath. Os goodwill impairments losses estão fortemente associados aos mecanismos de governança, e é provável que mecanismos de governança eficazes restringem a capacidade dos gestores de reportar goodwill impairment losses que difere das perdas econômicas previstas.

Outros achados mostram que companhias adquirentes envolvidas em F\&A stock-for-stock têm incentivos para práticas de EM visando a reduzir o custo total da transação. Essas companhias apresentam accruals anormais positivos em períodos que antecedem o anúncio da F\&A. Os resultados sugerem que o baixo desempenho das companhias adquirentes ex post às F\&A é parcialmente atribuído à reversão de preços dada pelo EM.

Uma descoberta importante foi que a associação negativa entre o desempenho de mercado pós-anúncio da F\&A e os accruals anor- 
mais pré-anúncio é substancialmente mais forte para os anunciantes de sextas-feiras do que para os anunciantes não sexta-feira. As evidências sugerem que a falta de atenção do investidor e o calendário estratégico dos anúncios e efetivação de eventos corporativos são potenciais razões pelas quais os investidores aparentemente não conseguem corrigir totalmente o EM.

Algumas pesquisas contrariam os resultados precedentes, pois não se encontraram evidências de que adquirentes praticam EM antes de F\&A. Nesses estudos constatou-se que, ex ante às F\&A, companhias adquirentes exibem níveis de desempenho operacional que excedem aquelas de seus respectivos setores; após a F\&A, elas continuam exibindo os mesmos níveis de desempenho.

Torna-se importante frisar que, para alguns autores, utilizar os accruals do balanço patrimonial para aferir o EM traz resultados conflitantes quando comparados aos estudos que utilizam os accruals calculados pela demonstração do fluxo de caixa. Os erros na estimação dos accruals pelo balanço patrimonial podem confundir os resultados das regressões que utilizam accruals como variáveis explicativas. Há evidências significativas de aumentos no lucro a partir de EM quando se utilizam accruals do balanço patrimonial. No entanto, para a mesma distribuição usando accruals estimados a partir da demonstração de fluxo de caixa não se constatou EM.

Por exemplo, estudos relatam que as companhias que utilizam ações como meio de financiamento em F\&A apresentam fluxos de caixa anormais negativos e despesas discricionárias anormais negativas, mas custos de produção anormais significativamente positivos durante o período corrente da F\&A. Os mesmos estudos apontam que as empresas adquirentes usam o real earnings management para aumentar os lucros objetivando melhorar a confiança do mercado; também há uma associação negativa entre o real earnings management e o baixo desempenho pós-F\&A.

Para trabalhos futuros são sugeridos estudos que relacionem information asymmetry com as transações de F\&A e as potenciais interferências nos resultados econômico-financeiros das empresas. Sob o ponto de vista de accounting information e value relevance, seria importante disponibilizar aos usuários das informações contábeis 
artefatos para que consigam prognosticar os futuros resultados das transações de F\&A.

Também seria importante abranger maior número de bases de periódicos para o levantamento de pesquisas sobre F\&A. É relevante esclarecer os impactos do EM para o risco e retorno das ações das empresas envolvidas nessas transações. Estudos que complementam as categorias analíticas aqui discutidas serão instigantes. Por exemplo, novas pesquisas que relatam relações entre EM, F\&A e compliance, fairvalue, conservadorismo, stock options, estrutura de propriedade, cobertura de analistas, behavioral accounting, pareceres de auditoria, diferenças entre EM por accruals e real earnings management etc.

Como limitações do presente estudo, pode-se dizer que a amostra analisada ficou restrita àqueles artigos publicados somente na base Web of Science; e, ainda que a definição das categorias analíticas tenha sido feita com base em metodologia prévia, não está totalmente isenta às limitações dos autores.

\section{REFERÊNCIAS}

ABUGHAZALEH, N. M.; AL-HARES, O. M.; ROBERTS, C. Accounting Discretion in Goodwill Impairments: UK Evidence. Journal of International Financial Management \& Accounting, v. 22, ed. 3, p. 165-204, 2011.

AMEL-ZADEH, A.; MEEKS, G.; MEEKS, J. G. Historical perspectives on accounting for M\&A. Accounting and Business Research, v. 46, ed. 5, edição especial: SI p. 501-524, 2016.

ANAGNOSTOPOULOU, S. C.; TSEKREKOS, A. E. Do firms that wish to be acquired manage their earnings? Evidence from major European countries. International Review of Financial Analysis, v. 30, p. 57-68, 2013.

. Earnings management in firms seeking to be acquired. British Accounting Review, v. 47, ed. 4 , p. 351-375, 2015.

BAIK, B.; CHO, K.; CHOI, W. The Role of Institutional Environments in Cross-Border Mergers: A Perspective from Bidders' Earnings Management Behavior. Management International Review, v. 55, ed. 5, p. 615-646, 2015.

BECKER, C. L. et al. The effect of audit quality on earnings management. Contemporary Accounting Research, Toronto, v. 15, n. 1, p. 1-24, Spring 1998.

BERETON, P. et al. Lessons from Applying the Systematic Literature Review Process within the Software Engineering Domain. The Journal of System and Software, v. 80, p. 571-583, 2007.

BERKOVITCH, E.; NARAYANAN, M. P. Motives for Takeovers: An Empirical Investigation. Journal of Financial and Quantitative Analysis, v. 28, n. 3, p. 347-362, sep. 1993. 
BIOLCHINI, J. C. A. et al. Scientific research ontology to support systematic review in software engineering. Advanced Engineering Informatics, v. 21, n. 2, p. 133-151, 2007.

BOTSARI, A.; MEEKS, G. Do Acquirers Manage Earnings Prior To a Share for Share Bid? Journal of Business Finance \& Accounting, v. 35, ed. 5-6, p. 633-670, jun./jul. 2008.

BRADLEY, M.; DESAI, A.; KIM, E. H. The rationale behind interfirm tender offers: information or synergy? Journal of Financial Economics, v. 11, Issues 1-4, p. 183-206, apr. 1983.

CAMPA, D.; HAJBABA, A. Do targets grab the cash in takeovers: The role of earnings management. International Review of Financial Analysis, v. 44, p. 56-64, mar. 2016.

CAMPBELL, J. T.; SIRMON, D. G.; SCHIJVEN, M. Fuzzy Logic and the Market: A Configurational Approach to Investor Perceptions of Acquisition Announcements. Academy of Management Journal, v. 59, n. 1, p. 163-187, feb. 2016.

CARUSO, G. D.; FERRARI, E. R.; PISANO, V. Earnings management and goodwill impairment - An empirical analysis in the Italian M\&A context. Journal of Intellectual Capital, v. 17, ed. 1, p. 120-147, 2016.

CHEN, S.-S.; LIU, Y.-C.; CHEN, I.-J. Long-Run Stock Performance and Its Determinants for Asset Buyers. Journal of Business Finance \& Accounting, v. 41, ed. 5-6, p. 685-716, 2014.

CHIU, P.-C.; TEOH, S. H.; TIAN, F. Board Interlocks and Earnings Management Contagion. Accounting Review, v. 88, ed. 3, p. 915-944, 2013.

CHRISTIE, A. A; ZIMMERMAN, J. L. Efficient and Opportunistic Choices of Accounting Procedures - Corporate-Control Contests. Accounting Review, v. 69, ed. 4, p. 539-566, 1994.

CUPERTINO, C. M.; MARTINEZ, A. L.; COSTA JR, N. C. A. da. Earnings manipulations by real activities management and investors' perceptions. Research in International Business and Finance, v. 34, p. 309-323, may. 2015.

DANIEL, K.; HIRSHLEIFER, D. Overconfident Investors, Predictable Returns, and Excessive Trading. The Journal of Economic Perspectives, v. 29, n. 4, p. 61-87, Fall 2015.

DECHOW, P. M.; SLOAN, R. G.; SWEENEY, A. P. Detecting earnings management. The Accounting Review, Sarasota, v. 70, n. 2, p. 193-225, apr. 1995.

DING, R.; JIA, Y. Auditor mergers, audit quality and audit fees: Evidence from the PricewaterhouseCoopers merger in the UK. Journal of Accounting and Public Policy, v. 31, ed. 1, p. 69-85, 2012.

DYE, R. Earnings management in an overlapping generations model. Journal of Accounting Research, Chicago, v. 26, n. 2, p. 195-235, Autumn 1988.

ERICKSON, M.; WANG, S. W. Earnings Management by Acquiring Firms in Stock for Stock Mergers. Journal of Accounting \& Economics, v. 27, ed. 2, p. 149-176, apr. 1999.

ESTORNIOLO FILHO, J. et al. Manual EndNote Web. Sistema Integrado de Bibliotecas SIBiUSP. São Paulo: USP, 2010.

FICH, E. M; RICE, E. M.; TRAN, A. L. Contractual revisions in compensation: Evidence from merger bonuses to target CEOs. Journal of Accounting \& Economics, v. 61, ed. 2-3, p. 338-368, 2016. 
FINFGELD-CONNETT, D.. Use of content analysis to conduct knowledge-building and theory-generating qualitative systematic reviews. Qualitative Research, v. 14, n. 3, p. 341-352, 2014.

GAVIOUS, I.; ROSENBOIM, M. The Disciplining Role of the Market Versus Government Regulation: The Case of Sarbanes-Oxley and the Earnings Quality of M\&A Targets. American Law and Economics Review, v. 15, ed. 1, p. 300-332, 2013.

GINER, B.; PARDO, F. How Ethical are Managers' Goodwill Impairment Decisions in Spanish-Listed Firms? Journal of Business Ethics, v. 132, ed. 1, p. 21-40, 2015.

GONG, G.; LOUIS, H.; SUN, A. X. Earnings Management, Lawsuits, And Stock-For-Stock Acquirers' Market Performance. Journal of Accounting \& Economics, v. 46, ed. 1, p. 62-77, sep. 2008.

GUO, S.; LIU, M. H.; SONG, W. Stock Splits as a Manipulation Tool: Evidence from Mergers and Acquisitions. Financial Management, v. 37, ed. 4, p. 695-712, 2008.

HEALY, P. M.; WAHLEN, J. M. A review of the earnings management literature and its implications for standard setting. Accounting Horizons, v. 13, n. 4, p. 365-383, dec. 1999.

HERON, R.; LIE, E. Operating Performance and The Method of Payment in Takeovers. Journal of Financial and Quantitative Analysis, v. 37, ed. 1, p. 137-155, mar. 2002.

HIGGINS, H. N. Do stock-for-stock merger acquirers manage earnings? Evidence from Japan. Journal of Accounting and Public Policy, v. 32, ed. 1, p. 44-70, 2013.

HRIBAR, P; COLLINS, D. W. Errors in Estimating Accruals: Implications for Empirical Research. Journal of Accounting Research, v. 40, ed. 1, p. 105-134, mar. 2002.

HSU, K. H. Y.; KIM, Y. S.; SONG, K. R. The Relation Among Targets' R\&D Activities, Acquirers' Returns, and In-Process R\&D in the US. Journal of Business Finance \& Accounting, v. 36, ed. 9-10, p. 1180-1200, 2009.

IRANI, R. M.; OESCH, D. Monitoring and corporate disclosure: Evidence from a natural experiment. Journal of Financial Economics, v. 109, ed. 2, p. 398-418, 2013.

. Analyst Coverage and Real Earnings Management: Quasi-Experimental Evidence. Journal of Financial and Quantitative Analysis, v. 51, ed. 2, p. 589-627, 2016.

JENSEN, M. C. Agency costs of free cash flow, corporate finance, and takeovers. American Economic Review, v. 76, n. 2, p. 323-329, may 1986.

JENSEN, M. C; MECKLING, W. H. Teoria da firma: comportamento dos administradores, custos de agência e estrutura de propriedade. RAE, v. 48, n. 2, p. 87-125, abr./jun. 2008.

JEONG, J. W.; BAE, G. Do acquiring firms knowingly pay too much for target firms? Evidence from earnings management in member-firm mergers in Korean business groups. Asia-Pacific Journal of Accounting \& Economics, v. 20, ed. 3, p. 223-251, 2013.

JONES, J. J. Earnings management during import relief investigations. Journal of Accounting Research, Chicago, v. 29, n. 2, p. 193-228, Autumn 1991.

KIMBROUGH, M. D.; LOUIS, H. Voluntary Disclosure to Influence Investor Reactions to Merger Announcements: An Examination of Conference Calls. Accounting Review, v. 86, ed. 2, p. 637-667, 2011. 
LEE, H.; KIM, S.; NAM, C. Earnings Management of Acquiring Firms in Stock-for-Stock Takeovers in the Telecommunications Industry. Journal of Media Economics, v. 21, ed. 4, p. 217-233, 2008.

LEHMANN, N. The role of corporate governance in shaping accruals manipulation prior to acquisitions. Accounting and Business Research, v. 46, ed. 4, p. 327-364, 2016.

LOUIS, H. Earnings Management and The Market Performance of Acquiring Firms. Journal of Financial Economics, v. 74, ed. 1, p. 121-148, oct. 2004.

. Are Stock-for-Stock Acquirers of Unlisted Targets Really Less Overvalued? Financial Management, v. 42, ed. 4, p. 901-929, 2013.

LOUIS, H.; SUN, A. X. Abnormal Accruals and Managerial Intent: Evidence from the Timing of Merger Announcements and Completions. Contemporary Accounting Research, v. 33, ed. 3, p. 1101-1135, 2016.

MARTINEZ, A. L. “Gerenciamento" dos resultados contábeis: estudo empírico das companhias abertas brasileiras. $150 \mathrm{f}$. Tese (Doutorado) - Faculdade de Economia, Administração e Contabilidade da Universidade de São Paulo, São Paulo, 2001.

MOHANRAN, P. S. How to manage earnings management? 2003. Disponível em: <http:// www.docstoc.com/docs/7175242/HOW-TO-MANAGE-EARNINGS-MANAGEMENT1>. Acesso em: 10 out. 2009.

RAMAN, K.; SHIVAKUMAR, L.; TAMAYO, A. Target's earnings quality and bidders' takeover decisions. Review of Accounting Studies, v. 18, ed. 4, p. 1050-1087, 2013.

ROLL, R. The hubris hypothesis of corporate takeovers. The Journal of Business, v. 59, n. 2, p. 197- 216, Part 1 (apr. 1986).

SAMPAIO, R. F.; MANCINI, M. C. Estudos De Revisão Sistemática: Um Guia Para Síntese Criteriosa da Evidência Científica. Revista Brasileira de Fisioterapia, São Carlos, v. 11, n. 1, p. 83-89, jan./fev. 2007.

SETH, A.; SONG, K. P.; PETTIT, R. Synergy, managerialism or hubris? An empirical examination of motives for foreign acquisitions of U.S. firms. Journal of International Business Studies, v. 31, Issue 3, p. 387-405, Third Quarter 2000.

SHLEIFER, A.; VISHNY, R. Management entrenchment: the case of manager-specific investments. Journal of Financial Economics, v. 25, Issue 1, p. 123-139, nov. 1989.

SUNDER, S. Knowing what others know: common knowledge, accounting and capital markets. Journal of Management Accounting Research, Sarasota, v. 16, n. 4, p. 305-319, dec. 2002.

TRAPP, A. C. G. A relação do conselho fiscal como componente de controle no gerenciamento de resultados contábeis. 133 f. Tese (Doutorado) - Faculdade de Economia, Administração e Contabilidade, Universidade de São Paulo, São Paulo, 2009. Disponível em: <http:// www.teses.usp.br/teses/disponiveis/12/12136/tde-08072009-160920/>. Acesso em: 20 fev. 2010.

VASILESCU, C.; MILLO, Y. Do industrial and geographic diversifications have different effects on earnings management? Evidence from UK mergers and acquisitions. International Review of Financial Analysis, v. 46, p. 33-45, jul. 2016. 
WANG, C.; XIE, F.; ZHU, M. Industry Expertise of Independent Directors and Board Monitoring. Journal of Financial and Quantitative Analysis, v. 50, ed. 5, p. 929-962, 2015.

WANG, T.; LIU, C.; CHANG, C. -H. J. CPA-Firm Merger: An Investigation of Audit Quality. European Accounting Review, v. 20, ed. 4, p. 727-761, 2011.

WESTON, J. F.; SIU, J. A.; JOHNSON, B. A. Takeovers, restructuring, and corporate governance. $3^{\underline{a}}$ ed. Pennsylvania: Prentice Hall, 2001.

XIE, Y.; YI, H. S.; ZHANG, Y. The Value of Big N Target Auditors in Corporate Takeovers. Auditing-A Journal of Practice \& Theory, v. 32, ed. 3, p. 141-169, 2013.

ZHANG, Z. Under-Performance of Listed Companies, Real Earnings Management and M\&A: Chinese Empirical Evidence. Journal of Industrial Engineering and Management-Jiem, v. 8, ed. 2, edição especial, SI, p. 322-334, 2015.

ZHAO, Y.; CHEN, K. H. The influence of takeover protection on earnings management. Journal of Business Finance \& Accounting, v. 35, ed. 3-4, p. 347-375, 2008.

Earnings quality effect of state antitakeover statutes. Journal of Accounting and Public Policy, v. 28, ed. 2, p. 92-117, 2009.

ZHAO, Y.; CHEN, K. H.; ZHANG, Y. Takeover protection and managerial myopia: Evidence from real earnings management. Journal of Accounting and Public Policy, v. 31, ed. 1, p. 109-135, 2012.

\section{APÊNDICE}

\section{Artigos analisados}

\begin{tabular}{|c|c|c|c|}
\hline Título & Autoria & Periódico & Ano \\
\hline $\begin{array}{l}\text { Efficient and Opportunistic } \\
\text { Choices of Accounting Pro- } \\
\text { cedures - Corporate-Control } \\
\text { Contests }\end{array}$ & $\begin{array}{l}\text { Christie, A. } \\
\text { A.; } \\
\text { Zimmerman, } \\
\text { J. L. }\end{array}$ & $\begin{array}{l}\text { Accounting Re- } \\
\text { view, v. } 69, \text { Ed: } 4, \\
\text { p. } 539-566\end{array}$ & 1994 \\
\hline $\begin{array}{l}\text { Earnings Management By } \\
\text { Acquiring Firms In Stock For } \\
\text { Stock Mergers }\end{array}$ & $\begin{array}{l}\text { Erickson, M.; } \\
\text { Wang, S. W. }\end{array}$ & $\begin{array}{l}\text { Journal of Accoun- } \\
\text { ting \& Economics, } \\
\text { v. } 27 \text {, ed. 2, p. 149- } \\
176\end{array}$ & 1999 \\
\hline $\begin{array}{l}\text { Operating Performance And } \\
\text { The Method Of Payment In } \\
\text { Takeovers }\end{array}$ & $\begin{array}{l}\text { Heron, R.; } \\
\text { Lie, E. }\end{array}$ & $\begin{array}{l}\text { Journal of Finan- } \\
\text { cial and Quanti- } \\
\text { tative Analysis, v. } \\
\text { 37, ed. 1, p. } 137-155 \\
\end{array}$ & 2002 \\
\hline $\begin{array}{l}\text { Errors In Estimating Ac- } \\
\text { cruals: Implications For } \\
\text { Empirical Research }\end{array}$ & $\begin{array}{l}\text { Hribar, P.; } \\
\text { Collins, D. } \\
\text { W. }\end{array}$ & $\begin{array}{l}\text { Journal of Accoun- } \\
\text { ting Research, v. } \\
\text { 40, ed. 1, p. 105-134 }\end{array}$ & 2002 \\
\hline
\end{tabular}




\begin{tabular}{|c|c|c|c|}
\hline $\begin{array}{l}\text { Earnings Management And } \\
\text { The Market Performance Of } \\
\text { Acquiring Firms }\end{array}$ & Louis, H. & $\begin{array}{l}\text { Journal of Finan- } \\
\text { cial Economics, v. } \\
74 \text {, ed. 1, p. 121-148 }\end{array}$ & 2004 \\
\hline $\begin{array}{l}\text { Do Acquirers Manage Ear- } \\
\text { nings Prior To A Share For } \\
\text { Share Bid? }\end{array}$ & $\begin{array}{l}\text { Botsari, A.; } \\
\text { Meeks, G. }\end{array}$ & $\begin{array}{l}\text { Journal of Busi- } \\
\text { ness Finance \& } \\
\text { Accounting, v. } 35 \text {, } \\
\text { ed. 5-6, p. } 633-670\end{array}$ & 2008 \\
\hline $\begin{array}{l}\text { Earnings Management, Law- } \\
\text { suits, And Stock-For-Stock } \\
\text { Acquirers' Market Perfor- } \\
\text { mance }\end{array}$ & $\begin{array}{l}\text { Gong, G.; } \\
\text { Louis, H.; } \\
\text { Sun, A. X. }\end{array}$ & $\begin{array}{l}\text { Journal of Accoun- } \\
\text { ting \& Economics, } \\
\text { v. } 46 \text {, ed. 1, p. } 62-77\end{array}$ & 2008 \\
\hline $\begin{array}{l}\text { Stock Splits as a Manipu- } \\
\text { lation Tool: Evidence from } \\
\text { Mergers and Acquisitions }\end{array}$ & $\begin{array}{l}\text { Guo, S.; } \\
\text { Liu, M. H.; } \\
\text { Song, W. }\end{array}$ & $\begin{array}{l}\text { Financial Manage- } \\
\text { ment, v. } 37, \text { ed. } 4 \text {, } \\
\text { p. } 695-712\end{array}$ & 2008 \\
\hline $\begin{array}{l}\text { Earnings Management of } \\
\text { Acquiring Firms in Stock-for } \\
\text {-Stock Takeovers in the Tele- } \\
\text { communications Industry }\end{array}$ & $\begin{array}{l}\text { Lee, H.; } \\
\text { Kim, S.; } \\
\text { Nam, C. }\end{array}$ & $\begin{array}{l}\text { Journal of Me- } \\
\text { dia Economics, v. } \\
\text { 21, ed. 4, p. 217-233 }\end{array}$ & 2008 \\
\hline $\begin{array}{l}\text { The influence of takeover } \\
\text { protection on earnings mana- } \\
\text { gement }\end{array}$ & $\begin{array}{l}\text { Zhao, Y.; } \\
\text { Chen, K. H. }\end{array}$ & $\begin{array}{l}\text { Journal of Busi- } \\
\text { ness Finance \& Ac- } \\
\text { counting, v. } 35 \text {, ed. } \\
3-4, \text { p. } 347-375\end{array}$ & 2008 \\
\hline
\end{tabular}

\section{Artigos analisados}

\begin{tabular}{|c|c|c|c|}
\hline Título & Autoria & Periódico & Ano \\
\hline $\begin{array}{l}\text { The Relation Among Targets' } \\
\text { R\&D Activities, Acquirers' } \\
\text { Returns, and In-Process R\&D } \\
\text { in the US }\end{array}$ & $\begin{array}{l}\text { Hsu, K. H. } \\
\text { Yu; } \\
\text { Kim, Y. S.; } \\
\text { Song, K. R. }\end{array}$ & $\begin{array}{l}\text { Journal of Busi- } \\
\text { ness Finance \& Ac- } \\
\text { counting, v. } 36 \text {, ed. } \\
9-10, \text { p. } 1180-1200\end{array}$ & 2009 \\
\hline $\begin{array}{l}\text { Earnings quality effect of } \\
\text { state antitakeover statutes }\end{array}$ & $\begin{array}{l}\text { Zhao, Y.; } \\
\text { Chen, K. H. }\end{array}$ & $\begin{array}{l}\text { Journal of Accoun- } \\
\text { ting and Public } \\
\text { Policy, v. 28, ed. 2, } \\
\text { p. } 92-117\end{array}$ & 2009 \\
\hline $\begin{array}{l}\text { Accounting Discretion in } \\
\text { Goodwill Impairments: UK } \\
\text { Evidence }\end{array}$ & $\begin{array}{l}\text { AbuGha- } \\
\text { zaleh, N. M.; } \\
\text { Al-Hares, O. } \\
\text { M.; } \\
\text { Roberts, C. }\end{array}$ & $\begin{array}{l}\text { Journal of Inter- } \\
\text { national Financial } \\
\text { Management \& } \\
\text { Accounting, v. } \\
\text { 22, ed. 3, p. 165-204 }\end{array}$ & 2011 \\
\hline
\end{tabular}




\begin{tabular}{|c|c|c|c|}
\hline $\begin{array}{l}\text { Voluntary Disclosure to In- } \\
\text { fluence Investor Reactions to } \\
\text { Merger Announcements: An } \\
\text { Examination of Conference } \\
\text { Calls }\end{array}$ & $\begin{array}{l}\text { Kimbrough, } \\
\text { M. D; } \\
\text { Louis, H. }\end{array}$ & $\begin{array}{l}\text { Accounting Re- } \\
\text { view, v. } 86 \text {, ed. } 2 \text {, } \\
\text { p. } 637-667\end{array}$ & 2011 \\
\hline $\begin{array}{l}\text { CPA-Firm Merger: An Inves- } \\
\text { tigation of Audit Quality }\end{array}$ & $\begin{array}{l}\text { Wang, T.; } \\
\text { Liu, C.; } \\
\text { Chang, C.-H. } \\
\text { J. }\end{array}$ & $\begin{array}{l}\text { European Accoun- } \\
\text { ting Review, v. } 20 \\
\text { ed. } 4, \text { p. } 727-761\end{array}$ & 2011 \\
\hline $\begin{array}{l}\text { Auditor mergers, audit qua- } \\
\text { lity and audit fees: Evidence } \\
\text { from the Pricewaterhouse- } \\
\text { Coopers merger in the UK }\end{array}$ & $\begin{array}{l}\text { Ding, R.; } \\
\text { Jia, Y. }\end{array}$ & $\begin{array}{l}\text { Journal of Accoun- } \\
\text { ting and Public } \\
\text { Policy, v. 31, ed. 1, } \\
\text { p. } 69-85\end{array}$ & 2012 \\
\hline $\begin{array}{l}\text { Takeover protection and } \\
\text { managerial myopia: Eviden- } \\
\text { ce from real earnings mana- } \\
\text { gement }\end{array}$ & $\begin{array}{l}\text { Zhao, Y.; } \\
\text { Chen, K. H.; } \\
\text { Zhang, Y. }\end{array}$ & $\begin{array}{l}\text { Journal of Accoun- } \\
\text { ting and Public } \\
\text { Policy, v. 31, ed. 1, } \\
\text { p. 109-135 }\end{array}$ & 2012 \\
\hline $\begin{array}{l}\text { Do firms that wish to be } \\
\text { acquired manage their ear- } \\
\text { nings? Evidence from major } \\
\text { European countries } \\
\end{array}$ & $\begin{array}{l}\text { Anagnosto- } \\
\text { poulou, S. C.; } \\
\text { Tsekrekos, } \\
\text { A. E. }\end{array}$ & $\begin{array}{l}\text { International Re- } \\
\text { view of Financial } \\
\text { Analysis, v. 30, p. } \\
57-68\end{array}$ & 2013 \\
\hline $\begin{array}{l}\text { Board Interlocks and Earnin- } \\
\text { gs Management Contagion }\end{array}$ & $\begin{array}{l}\text { Chiu, P.-C.; } \\
\text { Teoh, S. H.; } \\
\text { Tian, F. }\end{array}$ & $\begin{array}{l}\text { Accounting Re- } \\
\text { view, v. } 88, \text { ed. 3, } \\
\text { p. 915-944 }\end{array}$ & 2013 \\
\hline $\begin{array}{l}\text { The Disciplining Role of the } \\
\text { Market Versus Government } \\
\text { Regulation: The Case of Sar- } \\
\text { banes-Oxley and the Earnin- } \\
\text { gs Quality of M\&A Targets }\end{array}$ & $\begin{array}{l}\text { Gavious, I.; } \\
\text { Rosenboim, } \\
\text { M. }\end{array}$ & $\begin{array}{l}\text { American Law and } \\
\text { Economics Review, } \\
\text { v. 15, ed. 1, p. 300- } \\
332\end{array}$ & 2013 \\
\hline $\begin{array}{l}\text { Do stock-for-stock merger } \\
\text { acquirers manage earnings? } \\
\text { Evidence from Japan }\end{array}$ & $\begin{array}{l}\text { Higgins, H. } \\
\text { N. }\end{array}$ & $\begin{array}{l}\text { Journal of Accoun- } \\
\text { ting and Public } \\
\text { Policy, v. 32, ed. 1, } \\
\text { p. } 44-70\end{array}$ & 2013 \\
\hline $\begin{array}{l}\text { Monitoring and corporate } \\
\text { disclosure: Evidence from a } \\
\text { natural experiment }\end{array}$ & $\begin{array}{l}\text { Irani, R. M.; } \\
\text { Oesch, D. }\end{array}$ & $\begin{array}{l}\text { Journal of Finan- } \\
\text { cial Economics, } \\
\text { v. } 109 \text {, ed. } 2, \text { p. } \\
398-418\end{array}$ & 2013 \\
\hline
\end{tabular}




\begin{tabular}{|c|c|c|c|}
\hline $\begin{array}{l}\text { Do acquiring firms knowin- } \\
\text { gly pay too much for target } \\
\text { firms? Evidence from ear- } \\
\text { nings management in mem- } \\
\text { ber-firm mergers in Korean } \\
\text { business groups } \\
\end{array}$ & $\begin{array}{l}\text { Jeong, J. W.; } \\
\text { Bae, G. }\end{array}$ & $\begin{array}{l}\text { Asia-Pacific Jour- } \\
\text { nal of Accounting } \\
\text { \& Economics, v. } \\
\text { 20, ed. 3, p. 223-251 }\end{array}$ & 2013 \\
\hline $\begin{array}{l}\text { Are Stock-for-Stock Ac- } \\
\text { quirers of Unlisted Targets } \\
\text { Really Less Overvalued? }\end{array}$ & Louis, H.; & $\begin{array}{l}\text { Financial Manage- } \\
\text { ment, v. } 42 \text {, ed. } 4 \text {, } \\
\text { p. } 901-929\end{array}$ & 2013 \\
\hline $\begin{array}{l}\text { Target's earnings quality and } \\
\text { bidders' takeover decisions }\end{array}$ & $\begin{array}{l}\text { Raman, K.; } \\
\text { Shivakumar, } \\
\text { L.; } \\
\text { Tamayo, A. }\end{array}$ & $\begin{array}{l}\text { Review of Accoun- } \\
\text { ting Studies, v. } \\
\text { 18, ed. 4, p. 1050- } \\
1087\end{array}$ & 2013 \\
\hline $\begin{array}{l}\text { The Value of Big N Target } \\
\text { Auditors in Corporate Takeo- } \\
\text { vers }\end{array}$ & $\begin{array}{l}\text { Xie, Y.; } \\
\text { Yi, H. S.; } \\
\text { Zhang, Y. }\end{array}$ & $\begin{array}{l}\text { Auditing-A Jour- } \\
\text { nal of Practice \& } \\
\text { Theory, v. 32, ed. } \\
\text { 3, p. } 141-169\end{array}$ & 2013 \\
\hline $\begin{array}{l}\text { Long-Run Stock Performan- } \\
\text { ce and Its Determinants for } \\
\text { Asset Buyers }\end{array}$ & $\begin{array}{l}\text { Chen, S.-S.; } \\
\text { Liu, Y.-C.; } \\
\text { Chen, I-J. }\end{array}$ & $\begin{array}{l}\text { Journal of Busi- } \\
\text { ness Finance \& Ac- } \\
\text { counting, v. } 41 \text {, ed. } \\
5-6, \text { p. } 685-716\end{array}$ & 2014 \\
\hline $\begin{array}{l}\text { Earnings management in } \\
\text { firms seeking to be acquired }\end{array}$ & $\begin{array}{l}\text { Anagnosto- } \\
\text { poulou, S. C.; } \\
\text { Tsekrekos, } \\
\text { A. E. }\end{array}$ & $\begin{array}{l}\text { British Accounting } \\
\text { Review, v. } 47, \text { ed. } \\
4, \text { p. 351-375 }\end{array}$ & 2015 \\
\hline $\begin{array}{l}\text { The Role of Institutional En- } \\
\text { vironments in Cross-Border } \\
\text { Mergers: A Perspective from } \\
\text { Bidders' Earnings Manage- } \\
\text { ment Behavior }\end{array}$ & $\begin{array}{l}\text { Baik, B.; } \\
\text { Cho, K.; } \\
\text { Choi, W. }\end{array}$ & $\begin{array}{l}\text { Management Inter- } \\
\text { national Review, } \\
\text { v. } 55 \text {, ed. 5, p. } 615- \\
646\end{array}$ & 2015 \\
\hline $\begin{array}{l}\text { How Ethical are Managers' } \\
\text { Goodwill Impairment De- } \\
\text { cisions in Spanish-Listed } \\
\text { Firms? } \\
\end{array}$ & $\begin{array}{l}\text { Giner, B.; } \\
\text { Pardo, F. }\end{array}$ & $\begin{array}{l}\text { Journal of Bu- } \\
\text { siness Ethics, v. } \\
\text { 132, ed. 1, p.21-40 }\end{array}$ & 2015 \\
\hline $\begin{array}{l}\text { Industry Expertise of Inde- } \\
\text { pendent Directors and Board } \\
\text { Monitoring }\end{array}$ & $\begin{array}{l}\text { Wang, C.; } \\
\text { Xie, F.; } \\
\text { Zhu, M. }\end{array}$ & $\begin{array}{l}\text { Journal of Finan- } \\
\text { cial and Quanti- } \\
\text { tative Analysis, v. } \\
\text { 50, ed. 5, p. } 929-962\end{array}$ & 2015 \\
\hline
\end{tabular}




\section{Artigos analisados}

\begin{tabular}{|c|c|c|c|}
\hline Título & Autoria & Periódico & Ano \\
\hline $\begin{array}{l}\text { Under-Performance of Listed } \\
\text { Companies, Real Earnings } \\
\text { Management and M\&A: Chi- } \\
\text { nese Empirical Evidence }\end{array}$ & Zhang, Z. & $\begin{array}{l}\text { Journal of Industrial } \\
\text { Engineering and Ma- } \\
\text { nagement-Jiem, v. 8, } \\
\text { ed. 2, Edição Especial: } \\
\text { SI, p. 322-334 }\end{array}$ & 2015 \\
\hline $\begin{array}{l}\text { Historical perspectives on } \\
\text { accounting for M\&A }\end{array}$ & $\begin{array}{l}\text { Amel-Zadeh, } \\
\text { A.; } \\
\text { Meeks, G.; } \\
\text { Meeks, J. G. }\end{array}$ & $\begin{array}{l}\text { Accounting and Busi- } \\
\text { ness Research, v. 46, } \\
\text { ed. 5, Edição especial: } \\
\text { SI p. 501-524 }\end{array}$ & 2016 \\
\hline $\begin{array}{l}\text { Do targets grab the cash in } \\
\text { takeovers: The role of ear- } \\
\text { nings management }\end{array}$ & $\begin{array}{l}\text { Campa, D.; } \\
\text { Hajbaba, A. }\end{array}$ & $\begin{array}{l}\text { International Review } \\
\text { of Financial Analysis, } \\
\text { v. } 44, \text { p. } 56-64\end{array}$ & 2016 \\
\hline $\begin{array}{l}\text { Earnings management and } \\
\text { goodwill impairment An em- } \\
\text { pirical analysis in the Italian } \\
\text { M\&A context }\end{array}$ & $\begin{array}{l}\text { Caruso, G. D.; } \\
\text { Ferrari, E. R.; } \\
\text { Pisano, V. }\end{array}$ & $\begin{array}{l}\text { Journal of Intellectual } \\
\text { Capital, v. 17, ed. 1, p. } \\
120-147\end{array}$ & 2016 \\
\hline $\begin{array}{l}\text { Contractual revisions in } \\
\text { compensation: Evidence } \\
\text { from merger bonuses to } \\
\text { target CEOs }\end{array}$ & $\begin{array}{l}\text { Fich, E. M.; } \\
\text { Rice, E. M.; } \\
\text { Tran, A. L. }\end{array}$ & $\begin{array}{l}\text { Journal of Accoun- } \\
\text { ting \& Economics, v. } \\
\text { 61, ed. } 2-3, \text { p. } 338-368\end{array}$ & 2016 \\
\hline $\begin{array}{l}\text { Analyst Coverage and Real } \\
\text { Earnings Management: Qua- } \\
\text { si-Experimental Evidence }\end{array}$ & $\begin{array}{l}\text { Irani, R. M.; } \\
\text { Oesch, D. }\end{array}$ & $\begin{array}{l}\text { Journal of Financial } \\
\text { and Quantitative } \\
\text { Analysis, v. 51, ed. 2, } \\
\text { p. 589-627 }\end{array}$ & 2016 \\
\hline $\begin{array}{l}\text { The role of corporate gover- } \\
\text { nance in shaping accruals } \\
\text { manipulation prior to acqui- } \\
\text { sitions }\end{array}$ & Lehmann, N. & $\begin{array}{l}\text { Accounting and } \\
\text { Business Research, v. } \\
46 \text {, ed. } 4, \text { p. } 327-364\end{array}$ & 2016 \\
\hline $\begin{array}{l}\text { Abnormal Accruals and } \\
\text { Managerial Intent: Evidence } \\
\text { from the Timing of Merger } \\
\text { Announcements and Com- } \\
\text { pletions }\end{array}$ & $\begin{array}{l}\text { Louis, H.; } \\
\text { Sun, A. X. }\end{array}$ & $\begin{array}{l}\text { Contemporary Ac- } \\
\text { counting Research, v. } \\
\text { 33, ed. 3, p. 1101-1135 }\end{array}$ & 2016 \\
\hline $\begin{array}{l}\text { Do industrial and geogra- } \\
\text { phic diversifications have } \\
\text { different effects on earnings } \\
\text { management? Evidence from } \\
\text { UK mergers and acquisitions }\end{array}$ & $\begin{array}{l}\text { Vasilescu, C.; } \\
\text { Millo, Y. }\end{array}$ & $\begin{array}{l}\text { International Review } \\
\text { of Financial Analysis, } \\
\text { v. } 46, \text { p. } 33-45\end{array}$ & 2016 \\
\hline
\end{tabular}


Recebido em: 10-03-2017

Aprovado em: 26-04-2017

Avaliado pelo sistema double blind review.

Editor: Elmo Tambosi Filho

Disponível em http://mjs.metodista.br/index.php/roc 